\title{
Influence of compounding conditions, treatment of wood particles with fire-retardants and artificial weathering on properties of wood-polymer composites for façade applications
}

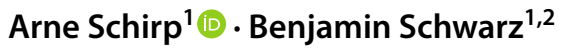 \\ Received: 30 May 2020 / Accepted: 26 March 2021 / Published online: 13 April 2021 \\ (c) The Author(s) 2021
}

\begin{abstract}
Various fire-retardants (FR) for the pre-treatment of wood flour, for example, ammonium polyphosphate and different formulations based on phosphorus- and nitrogen-compounds, as well as for application during compounding were tested for their effectiveness in injection-molded and extruded composites based on high-density polyethylene and polypropylene. Small-scale tests for flammability of polymeric materials and for determination of the limiting oxygen index were used to characterize the composite materials. Differences pertaining to the applied compounding conditions, i.e., underwater granulation versus air granulation, were determined. The amount of phosphorus leached from FR during underwater granulation was analyzed. Artificial weathering trials were performed and reaction-to-fire performance and color changes of FR-composites were evaluated. Tensile strength properties of the composites and results for cold water immersion tests are also reported. An optimized formulation based on pre-treated wood flour was developed and extruded into façade profiles for the single burning item test according to DIN EN 13823. The test showed that classification C-s3, d0 according to DIN EN 13501-1 can be achieved if pre-treated wood flour is used. The use of untreated wood flour leads to a lower classification (D-s2, d0). Fire performance of extruded façade profiles can be improved by the use of pre-treated wood flour and enables new applications in the building sector.
\end{abstract}

\section{Introduction}

Wood-polymer composites (WPC) are classified as normally flammable if they do not contain any fire-retardants. To improve the reaction-to-fire performance of WPC, several strategies can be used: bulk (mass) protection with fireretardants (FR), pre-treatment of the wood particles with $\mathrm{FR}$, application of a fire-retardant coating, and co-extrusion with FR only in the outer layer of the profile. The selected strategy depends on the type of polymer, amount of wood particles in the formulation and processing equipment available. A pre-treatment of the wood particles was pursued by Seefeldt and Braun (2012a, b). They impregnated unspecified wood flakes with a salt of a phosphoric acid derivative

Arne Schirp

arne.schirp@wki.fraunhofer.de

1 Fraunhofer-Institute for Wood Research (WKI), Bienroder Weg 54E, 38108 Braunschweig, Germany

2 Present Address: GOM GmbH, Schmitzstraße 2, 38122 Braunschweig, Germany
(Disflamoll TP LXS 51064, Lanxess, Germany) and studied the interaction of the FR and a WPC material based on $40 \mathrm{wt} \%$ polypropylene. Cone calorimetric measurements showed that the fire behaviour of the composite material including the FR was improved compared to unprotected material. The effects of the FR were also investigated in detail by using thermogravimetry and FTIR spectroscopy.

Hämäläinen and Kärki (2014) treated spruce wood flour with two different phosphate-based FR solutions and melamine formaldehyde resin prior to combining the wood flour with polypropylene via direct extrusion. Although the fire performance was improved by wood modification, the mechanical performance of the composites deteriorated. In general, modification of wood flour for application in WPC can be accomplished, for example, by acetylation (Ibach et al. 2007), heat treatment (Ayrilmis et al. 2011), benzylation (Dominkovics et al. 2007) or treatments with silanes (Xie et al. 2013). However, these treatments were mainly focused on improving the mechanical performance, to reduce water uptake and swelling and decay resistance, while impoved fire retardancy of WPC has not been sought. 
In a recent publication by Yin et al. (2018), different routes to obtain halogen-free flame-retardant WPC based on polypropylene were investigated. All WPC with singlecomponent flame retardants improved limiting oxygen index (LOI) values but achieved only HB classification in UL 94 tests. Fire properties and fire spread characteristics were improved by using mixtures of FR. The best overall results were obtained with mixtures based on $15 \mathrm{wt} \%$ expandable graphite (EG) or combinations of EG and ammonium polyphosphate (APP) at different ratios.

In another recent study, the reaction-to-fire performance of WPC made with recycled plastics was investigated using the cone calorimeter (Turku et al. 2018). Surprisingly, the composites based on recycled plastic were more thermostable than the ones based on virgin polymers. The peak heat release rate (pHRR) of the composites with recycled material was $12-25 \%$ lower which was attributed to the presence of additives in the recyclates, such as pigments and FR, as well as impurities from landfills.

Detailed information regarding the flammability of biofibres and biocomposites, strategies to achieve fire retardancy for natural-fiber reinforced composites and information regarding the mode of action of different flame retardants can be found in Kozlowski and Wladyka-Przybylak (2008), Chapple and Anandjiwala (2010), Nikolaeva and Kärki (2011) and Mngomezulu et al. (2014). In general, two possible actions for a fire-retardant can be distinguished which are based on chemical or physical principles. A chemical action is targeted at interfering with free radical reactions which take place during burning (gas phase) and aim to protect internal materials from heating during char creation (solid phase). Physical actions are based on decreasing the temperature by endothermic reactions, reducing the fire distribution by fluxing oxygen with non-combustible gases. In addition, the formation of a protective surface layer is promoted.

It has been shown that the wood flour or fibre itself acts as a fire-retardant for the polymer matrix in WPC, with heat release rates decreasing as the amount of wood filler increases (Spear 2015). The heat release rate (HRR) of PP is $43 \mathrm{MJ} \mathrm{kg}^{-1}$ whereas pine wood has HRR of $19 \mathrm{MJ} \mathrm{kg}^{-1}$. The presence of wood also promotes the formation of a char layer on the WPC surface (Seefeldt and Braun 2012a).

In a previous research project, wood particles from fireretardant-treated particleboard were successfully combined with thermoplastics to improve the reaction-to-fire performance of WPC (Schirp and Su 2016). Pre-treatment of thermomechanical pulp with APP was also effective to increase the fire performance of extruded profiles (Schirp and Hellmann 2019). So far, the best classification (B-s2, d0) in singleburning item (SBI) tests was achieved by using a high wood content, a pre-treatment of the wood particles with FR and by using APP as fire-retardant (Schirp and Barrio 2018). More experimental data are required to improve our knowledge regarding the reaction-to-fire performance of WPC, especially based on large-scale tests such as the single-burning item test (SBI) according to DIN EN 13823 (2002). An important aspect which also merits further investigation is the durability of the fire-retardant treatment in WPC. It is not known yet if and to which extent fire-retardants may leach from WPC during processing and/or service life. Often, underwater granulation is used to produce granulates (pellets, compounds) for profile extrusion or injection-moulding. Potentially, FR can leach during contact with water. It was one of the objectives of this project to determine if leaching of the fire-retardant occurs when underwater granulation is used, and if this affects the reaction-to-fire performance of the materials. The underwater pelletizing system consists of a polymer diverter valve, a pelletizing unit, a water treatment and drying system and an electrical control system. The melt is flowing from the extruder to the polymer diverter valve of the underwater granulation unit and is pressed through the holes of the die plate. The strands are cut into granules directly after their exit from the die plate by rotating knives. This is occurring in the cutting chamber which is completely flooded with water. The granules are hardened due to their contact with the process water which is running over the front part of the die plate. The process water transports the granules to the centrifugal dryer where they are separated from the water and discharged. The process water is in a completely closed circulating system, hence, water loss is minimal. To analyze if leaching of the fire-retardants occurs during processing, in this project, the process water was collected during compounding and analyzed.

In summary, the objectives were to select FR for the treatment of wood particles before compounding and for the polymer matrix during compounding, to determine a potential benefit of using FR-treated wood particles, and to determine leaching of the FR during processing (compounding with underwater granulation) and during short-term weathering. The reaction-to fire performance of injectionmoulded, small-scale samples as well as of large, extruded façade profiles was investigated. The selection of FR for the wood flour was done based on products available for wood particles, fibres, cellulose, paper and textiles. Preferably, the fire-retardants should be available in liquid form and halogen-free. For protection of the polymer matrix, various commercially available, halogen-free FR were sourced and tested.

\section{Materials and methods}

\subsection{Materials}

High-density polyethylene (HDPE), polypropylene (PP) and wood flour were used as main components for WPC. 
Softwood flour with a main particle size between 200 and $500 \mu \mathrm{m}$ (Arbocel C320, J. Rettenmaier \& Söhne $\mathrm{GmbH}+\mathrm{CO}$, Rosenberg, Germany) was used as filler for WPC. A high-density polyethylene (HDPE) in powder form (56020S, Total Petrochemicals, Brussels, Belgium) with an average particle size of $800 \mu \mathrm{m}$, density of $0.952 \mathrm{~g} / \mathrm{cm}^{3}$ and a melt flow rate $\left(190{ }^{\circ} \mathrm{C} ; 21.6 \mathrm{~kg}\right)$ of $2.1 \mathrm{~g} / 10 \mathrm{~min}$ was used. The PP type was PPH 9000 OG (homopolymer, off-grade type of PPH 9069, Total Petrochemicals) in pellet form with a density of $0.905 \mathrm{~g} / \mathrm{cm}^{3}$ and a melt flow index $\left(230{ }^{\circ} \mathrm{C}\right.$; $2.16 \mathrm{~kg}$ ) of $23.9 \mathrm{~g} / 10 \mathrm{~min}$.

The coupling agent for the HDPE-based composites was a maleic-anhydride-grafted, linear, low density polyethylene (MAPE) in powder form with MA-content of $1.5 \%(\mathrm{wt})$ (Scona TPPE 1102 PALL, BYK Kometra, Schkopau, Germany). For PP, a maleic-anhydride-grafted PP (MAPP) with MA-content of 1.4\% (Scona TPPP 8112 FA, BYK Kometra) was used. Further additives were a blend of complex, modified fatty acid ester (TPW 113, Struktol, provided by Velox, Hamburg) used as lubricant, a UV stabilizer (Irganox B225, BASF) and a brown colour masterbatch on PE basis (74445F $\mathrm{PE}$, Lifocolor GmbH, Lichtenfels).

Fire-retardants for the treatment of wood flour were ammonium polyphosphate (APP, Exolit AP 420, Clariant, Germany; phosphorus content between 12.5 and 13.5\%), a nitrogen-containing salt of phosphonic acid (Aflammit MSG, Thor, Germany), zinc borate (Zinborel, Omya, Cologne, Germany), five different formulations based on Pand N-compounds (Apyrol BKW and Apyrol NCE CONC. by CHT R. Breitlich GmbH, Tübingen, Germany; VP 25623, VP 25629 and VP 25628 by IGP Ingenieurbüro Große Perdekamp, Dülmen, Germany), an organophosphorous compound (Disflamoll TP LXS 51064, Lanxess, Germany), alkali silicate (waterglass, Betol 39 T3, Wöllner, Germany), and a non-commercial by-product of the aluminum diethyl phosphinate (DEPAL) production in slurry form (Clariant, Germany). In case of the alkali silicate, this liquid was also used in combination with a catalyst (ammonium hydroxide) to accelerate the reaction with the wood flour.

The fire-retardants used for the polymer matrix were APP (Exolit AP 422, Clariant; phosphorus content 31-32\%) and APP micro-encapsulated with melamine (Exolit AP 462, Clariant; phosphorus content $30.7 \%$ ). In addition, the following fire-retardants were used: melamine cyanurate (Melapur MC 25, BASF, Germany); a combination of piperazine pyrophosphate, phosphoric acid and zinc oxide (AKD-STAB-FP-2200S, Adeka) which was provided as masterbatch (70\% ADK-STAB-FP-2200S in a PP matrix; Mastertek GR5351, Campine, Beerse, Belgium); zinc borate (Zinborel, Omya GmbH, Cologne, Germany); magnesium hydroxide (Magnifin H5 MV; Magnifin Magnesiaprodukte, Breitenau am Hochlantsch, Austria); and a dispersion of phosphorus and nitrogen in PP (Vibatan HF 04626, W\&R
Plastics). A by-product from the aluminum diethyl phosphinate (DEPAL) production (provided by Clariant) was also used as FR following drying and grinding of the slurry. Where indicated, pentaerythritol (Penta technical grade, micronized powder, Perstorp) was used as carbonific agent and melamine in powder form as blowing agent (Melafine, DSM, Geleen, Netherlands) in combination with APP.

\subsection{Processing}

Fire retardants (10 wt $\%$ or $20 \mathrm{wt} \%$, based on solids content and dry wood flour) were added to the wood flour by using a spray nozzle attached to a plough-blade mixer. Three kg-batches with the different FR were prepared. Afterwards, batches were dried in an oven for $12 \mathrm{~h}$ at $30{ }^{\circ} \mathrm{C}$. Treated wood flour was pressed into small samples $(80 \mathrm{~mm} \times 10 \mathrm{~mm} \times 4 \mathrm{~mm})$ using a self-made tool in a hot press. These samples were used for determination of the limiting oxygen index (LOI).

A co-rotating twin screw extruder (TSK 20, Theysohn Maschinenbau, Salzgitter, Germany) was used for compounding untreated or treated wood flour, HDPE or PP, fireretardants and additives. Fourteen formulations (Table 1) were prepared using either underwater or air granulation (EUP-ELG 50, ECON, Weisskirchen, Austria), hence, in total, 28 formulations were processed and designated as UWG (under water granulation) or AG (air granulation). The designation was done according to the FR used for wood flour and polymer matrix, for example, AP420-AP422 means that the wood flour was treated with AP420 and the polymer matrix with AP422. The process water (eluate) during underwater granulation was collected for analysis (leaching of phosphorus).

Before injection-moulding, granulates were dried to a moisture content of approximately $1 \%$ and converted into smaller granules using a cross beater mill. A miniinjection moulding machine (HAAKE Minijet II, Thermo Fisher Scientific, Karlsruhe, Germany) equipped with a self-designed mould was used to prepare specimens of $80 \mathrm{~mm} \times 10 \mathrm{~mm} \times 4 \mathrm{~mm}$ for determination of LOI, UL 94-classification, artificial weathering and water uptake and swelling after 28 days of cold water immersion. Specimens of type 1A (DIN EN 527-2) with $4 \mathrm{~mm}$ thickness were prepared for tensile strength tests. Ten specimens were prepared for each of the tests. Processing parameters for injectionmoulding are shown in Table 2. Settings were identical for most formulations, with the exception of two formulations which had to be processed with lower temperatures.

For industrial-scale extrusion trials, $180 \mathrm{~kg}$ of wood particles (Arbocel C320) were treated with 10\% Apyrol NCE Conc. (based on solid content and wood dry weight) and dried to $5.5 \%$ moisture content by company Rettenmaier \& Söhne (Rosenberg, Germany). The wood particles 
Table 1 Formulations based on HDPE and PP

\begin{tabular}{llllllll}
\hline Designation & $\begin{array}{l}\text { WF, } \\
\text { untreated } \\
(\%)\end{array}$ & $\begin{array}{l}\text { WF with } \\
\text { exolit AP 420 } \\
(\%)\end{array}$ & $\begin{array}{l}\text { WF with apyrol } \\
\text { NCE conc (\%) }\end{array}$ & $\begin{array}{l}\text { HDPE (\%) } \\
\text { WP (\%) }\end{array}$ & $\begin{array}{l}\text { Exolit AP } \\
422(\%)\end{array}$ & $\begin{array}{l}\text { Exolit } \\
\text { AP 462 } \\
(\%)\end{array}$ \\
\hline Without FR & 58 & 0 & 0 & 33 & 0 & 0 & 0 \\
No FR-AP422 & 42 & 0 & 0 & 33 & 0 & 16 & 0 \\
No FR-AP462 & 42 & 0 & 0 & 33 & 0 & 0 & 16 \\
AP420-AP422 & 0 & 42 & 0 & 33 & 0 & 16 & 0 \\
AP420-AP462 & 0 & 42 & 0 & 33 & 0 & 0 & 16 \\
Apyrol-AP422 & 0 & 0 & 42 & 33 & 0 & 16 & 0 \\
Apyrol-AP462 & 0 & 0 & 42 & 33 & 0 & 0 & 16 \\
Without FR & 58 & 0 & 0 & 0 & 33 & 0 & 0 \\
No FR-AP422 & 42 & 0 & 0 & 0 & 33 & 16 & 0 \\
No FR-AP462 & 42 & 0 & 0 & 0 & 33 & 0 & 16 \\
AP420-AP422 & 0 & 42 & 0 & 0 & 33 & 16 & 0 \\
AP420-AP462 & 0 & 42 & 0 & 0 & 33 & 0 & 16 \\
Apyrol-AP422 & 0 & 0 & 42 & 0 & 33 & 16 & 0 \\
Apyrol-AP462 & 0 & 0 & 42 & 0 & 33 & 0 & 16 \\
\hline
\end{tabular}

Percentages represent wt $\%$. Wood flour (WF) was treated with $10 \%$ of fire-retardant (FR) based on solids content and dry wood before compounding. In addition, in each formulation, 3\% coupling agent (MAPE or MAPP), 3\% lubricant, $2.75 \%$ colour masterbatch and $0.25 \%$ UV stabilizer were included

Table 2 Process parameters during injection moulding

\begin{tabular}{lllllll}
\hline Formulation & $\begin{array}{l}\text { Cylinder } \\
\text { temperature } \\
\left({ }^{\circ} \mathrm{C}\right)\end{array}$ & $\begin{array}{l}\text { Tool tem- } \\
\text { perature } \\
\left({ }^{\circ} \mathrm{C}\right)\end{array}$ & $\begin{array}{l}\text { Injection } \\
\text { pressure } \\
(\text { bar })\end{array}$ & $\begin{array}{l}\text { Process- } \\
\text { ing time } \\
(\mathrm{s})\end{array}$ & $\begin{array}{l}\text { Post- } \\
\text { processing } \\
\text { time }(\mathrm{s})\end{array}$ & $\begin{array}{l}\text { Post } \\
\text { pressure } \\
(\text { bar })\end{array}$ \\
\hline $\begin{array}{l}\text { PP-based: AP420-AP422; } \\
\text { Apyrol-AP422; Apyrol- } \\
\text { AP462 }\end{array}$ & 190 & 70 & 700 & 6 & 6 & 650 \\
All other formulations & 210 & 80 & 700 & 6 & 6 & 650 \\
\hline
\end{tabular}

were compounded by company Linotech (Forst, Germany) into the HDPE-based formulation Apyrol-AP422 using a strand granulation process. The corresponding formulation without wood particle treatment but including 16\% APP for the HDPE matrix was also processed. Siding (façade) profiles were extruded by company Natur-in-Form (Redwitz, Germany) using a $68 \mathrm{~mm}$ conical, counter-rotating extruder (Battenfeld-Cincinnati). Full siding profiles (without hollow chambers) of $18 \mathrm{~mm}$ thickness and a visual height of $58 \mathrm{~mm}$ width were extruded. Small samples $(80 \mathrm{~mm} \times 10 \mathrm{~mm} \times 4 \mathrm{~mm})$ were cut from the profiles for LOI and UL 94-tests. Extruded profiles were used for the single-burning item test.

\subsection{Test methods}

\subsubsection{Oxygen index, UL94 tests and artificial weathering}

Specimens were conditioned at $20 \pm 2{ }^{\circ} \mathrm{C}$ and $65 \pm 5 \%$ relative humidity for four days prior to LOI tests, UL 94 determination and mechanical tests. The oxygen index test measures the minimum concentration of oxygen in a flowing mixture of oxygen and nitrogen that will just support flaming combustion. Determination of the LOI was done according to modified DIN EN ISO 4589-2: 2006. A small test specimen is supported vertically in an oxygen-nitrogen mixture that is flowing upward through a glass column. The upper end of the specimen is ignited, and the subsequent burning behavior of the specimen is observed. Basically, if a test specimen is hard to burn, it requires more oxygen to cause flaming combustion, and this increases its oxygen index. Horizontal and vertical UL94-tests were performed according to modified DIN EN 60695-11-10 (2014) using five conditioned test samples per formulation. The modification consisted in smaller specimen size $(80 \mathrm{~mm}$ instead of $125 \mathrm{~mm}$ length) and the omission of a cotton pad under the test sample. However, development of burning droplets was carefully monitored by visual observation. LOI and UL94 tests were also performed after $300 \mathrm{~h}$ of artificial weathering under xenon-lamps in a Suntest XXL device (Atlas) according to DIN EN ISO 4892-2A (2009), cycle 1. After weathering, specimens were conditioned at $20{ }^{\circ} \mathrm{C}$ and $65 \%$ relative humidity for $72 \mathrm{~h}$, and color measurements were taken as described in Schirp et al. (2015). 


\subsubsection{Tensile properties, water uptake and swelling}

Tensile properties, water uptake and swelling of the test specimens after 28 days of cold water immersion were determined according to DIN EN 15534-1 (2018). Tensile strength tests were performed according to DIN EN ISO 527-2 (2012) with dog-bone shaped samples of $4 \mathrm{~mm}$ thickness (type 1A) using a material testing machine (BZ1-MM14740.ZW01, Zwick, Ulm, Germany) and corresponding software (TestXpert II). Rate of elongation was $1 \mathrm{~mm} \mathrm{~min}{ }^{-1}$ for the tensile modulus of elasticity and $50 \mathrm{~mm} \mathrm{~min}^{-1}$ for the tensile strength. Measurement of the dimensions in thickness, width and length of the specimens $(80 \mathrm{~mm} \times 10 \mathrm{~mm} \times 4 \mathrm{~mm})$ was taken 28 days after the immersion into water at a temperature of $20^{\circ} \mathrm{C}$. Water uptake was determined by differential weighing of the test specimens.

\subsubsection{Single burning item (SBI) tests}

Single burning item (SBI) tests were performed according to DIN EN 13823 (2002). During SBI testing, the base layer consisted of non-flammable calcium silicate panels with $10 \mathrm{~mm}$ thickness. Aluminum profiles were fixed on the panels with screws, and the extruded profiles were inserted into clips which were mounted on the aluminum profiles. According to DIN EN 13823, in the longer of the two parts, there shall be a vertical and a horizontal zero-joint. Because of the presence of horizontal joints throughout the façade set-up, only a vertical joint was included.

The classification parameters of the SBI test are fire growth rate index (FIGRA), lateral flame spread (LFS), and total heat release $\left(\mathrm{THR}_{600 \mathrm{~s}}\right)$. Additional classification parameters are defined for smoke production as smoke growth rate index (SMOGRA) and total smoke production $\left(\mathrm{TSP}_{600 \mathrm{~s}}\right)$, and for flaming droplets and particles according to their occurrence during the first $600 \mathrm{~s}$ of the test. The FIGRA and SMOGRA indices were calculated as follows:

$F I G R A=1000 \max \left(\frac{\operatorname{HRRav}(t)}{t}\right)$

$\operatorname{SMOGRA}=1000 \max \left(\frac{\operatorname{SPRav}(t)}{t}\right)$

where $\mathrm{HRR}_{\mathrm{av}}$ is the heat release rate averaged over $30 \mathrm{~s}$ (in $\mathrm{kW}), \mathrm{SPR}_{\mathrm{av}}$ is the smoke production rate averaged over $60 \mathrm{~s}$ (in $\mathrm{m}^{2} / \mathrm{s}$ ), and $t$ is the time elapsed after the beginning of the test (in s). The units of FIGRA and SMOGRA are W/s and $\mathrm{m}^{2} / \mathrm{s}^{2}$, respectively. Heat release-related threshold values for the FIGRA calculation were used to obtain FIGRA $_{0,2} \mathrm{MJ}$ and FIGRA $A_{0,4 \mathrm{MJ}}$ values. THR $600 \mathrm{~s}$ and $\mathrm{TSP}_{600 \mathrm{~s}}$ values were calculated over the first $600 \mathrm{~s}$ of the test as follows:
$T H R 600 s=\frac{1}{1000} \sum_{0 s}^{600 s} H R R(t) \Delta t$

$T S P 600 s=\sum_{0 s}^{600 s} \operatorname{SPR}(t) \Delta t$

where $\operatorname{HRR}(t)$ and $\operatorname{SPR}(t)$ are the heat release rate and smoke production rate as functions of time (in $\mathrm{kW}$ and $\mathrm{m}^{2} / \mathrm{s}$, respectively), and $\Delta \mathrm{t}$ is the data acquisition interval of the measurement (in s). The units of $\mathrm{THR}_{600 \mathrm{~s}}$ and $\mathrm{TSP}_{600 \mathrm{~s}}$ are $\mathrm{MJ}$ and $\mathrm{m}^{2}$, respectively. The obtained SBI results were compared with the classification criteria according to EN 13501-1 (2010).

\subsubsection{Thermogravimetric analysis}

Thermal stability of selected compounds was investigated by means of thermogravimetric analysis (TGA) using a TGA/ DSC 1 (Mettler-Toledo AG, Schwerzenbach, Switzerland). Samples (approx. $10 \mathrm{mg}$ ) were weighed into a TGA crucible and subsequently placed in the TGA instrument. Samples were heated from 25 to $1000{ }^{\circ} \mathrm{C}$ at a heating rate of $10 \mathrm{~K} \cdot \mathrm{min}^{-1}$ under a constant air flow of $50 \mathrm{~mL} \cdot \mathrm{min}^{-1}$.

\subsubsection{Leaching of phosphorous from fire-retardants during underwater granulation}

The process water (eluate) collected during underwater granulation was analyzed for phosphorus content using inductively coupled plasma optical emission spectrometry (ICPOES) according to DIN EN ISO 11885 (2009). The amount of leached phosphorous served as an indication how much of the FR was released during processing. During ICP-OES, the samples are atomized and the produced aerosol is transported into a plasma torch where the elements are excited. Using the plasma generated by inductive high frequency coupling, characteristic emission spectra are generated. The spectra are divided into lines by a grating spectrometer and analysed using a detector.

\section{Results and discussion}

\subsection{Evaluation of fire-retardants for treatment of wood particles and polymer matrix for use in WPC}

First, suitable fire-retardants were evaluated separately for the treatment of wood particles and polymer matrix. For evaluation of the wood particle treatments, the oxygen index test was chosen as method. The oxygen index is generally recognized as an indication of general flammability. Highly 
flammable materials display a low oxygen index. The more oxygen required (the higher the LOI value), the more fireresistant the material is considered to be. Since air contains $21 \%$ oxygen, polymeric materials with an LOI value lower than 21 are categorized as combustible whereas those with LOI above 21 are classified as self-extinguishing because their combustion cannot be maintained at ambient temperature without the contribution of an external energy source (Kiliaris and Papaspyrides 2014). The oxygen index test is widely used in the plastics industry but has also been used to evaluate fire-retardant treated wood and wood products (White 1979). Results for LOI of pressed wood flour samples which were pre-treated with different FR are shown in Table 3. Overall, LOI was between 27 and 68. This is generally in the same range as results obtained by White (1979) for fire-retardant treated wood products. In Table 3, results for LOI with either $10 \%$ or $20 \%$ of FR are shown. Two concentrations of FR were tested to determine if LOI increases with higher amount of applied FR. The three FR which resulted in the highest LOI were APP (LOI: 66-67) as well as P- and N-containing compounds (LOI: 67-68). For comparison, untreated pine wood and FR-treated particleboard display an LOI of 21-22 and 68-80, respectively (Schirp and Su 2016). Phosphorus-based compounds are some of the best known fire-retardant treatments for timber and wood products. They are considered to act mainly in the condensed phase, by promoting char formation and depriving the gas phase of further volatile decomposition products (Lowden and Hull 2013).

Under the conditions of the current experiments, zinc borate, alkali silicate and DEPAL displayed the lowest values for LOI when the FR were applied to wood particles alone. Zinc borate has relatively low solubility in water and can be easily blended with particles or strands, hence, it has often been used in the production of particleboard and OSB (Spear 2015). It has mainly been used for exterior panel products due to its low solubility. Zinc borate treatments are commonly used in the processing of WPC since they also show broad spectrum activity against wood destroying organisms and demonstrate a good environmental profile. The heat decomposition of zinc borate leads to the creation of a glassy protection layer which acts as a barrier for polymer chain oxidation (Nikolaeva and Kärki 2011). Another benefit of zinc borate is its good smoke suppressant property.

Alkali (sodium) silicate or waterglass has been used as fire-retardant coating component and as impregnation solution for wood products (Lowden and Hull 2013). The LOI of pressed wood samples with alkali silicate was slightly higher (36-37) than with zinc borate and could be further increased with ammonium hydroxide as catalyst (46-47), however, values for LOI were not as high as with some of the $\mathrm{P}$ - and N-containing compounds. The product used here was Betol $39 \mathrm{~T} 3$ (Woellner) which according to the technical data sheet is an inorganic binder based on modified sodium silicate with special additives. It is possible that higher temperature during pressing of the samples is needed to achieve a fire-retarding effect in the wood particles, or that a suitable hardener is needed. Usually, Betol 39 T3 is applied as binder for the production of insulating, fire protecting and other construction panels, and can be cured by organic or inorganic hardeners, acidic gases (e.g. $\mathrm{CO}_{2}$ ) or higher temperatures.

Disflamoll TP LXS 51064 (Lanxess), a salt of a phosphoric-acid derivate, displayed intermediate values for the LOI and was close to the performance of the alkali silicate with catalyst and one of the products with P- and

Table 3 Oxygen index of pressed wood flour samples pre-treated with different FR

\begin{tabular}{llll}
\hline Type of FR & Chemical basis of FR & LOI with 10\% FR & LOI with 20\% FR \\
\hline Exolit AP 420 (Clariant) & APP & $53-54$ & $\mathbf{6 6 - 6 7}$ \\
Aflammit MSG (Thor) & Nitrogen-containing salt of phosphonic acid & $42-43$ & $59-60$ \\
Zinborel (SCL) & Zinc borate & Not tested & $27-28$ \\
Apyrol BKW (CHT Bezema) & P- and N-containing compounds & $37-38$ & $40-41$ \\
Apyrol NCE conc. (CHT Bezema) & P- and N-containing compounds & $38-39$ & $\mathbf{6 7 - 6 8}$ \\
VP 25623 (IGP) & P- and N-containing compounds & $38-39$ & $64-65$ \\
VP 25629 (IGP) & P- and N-containing compounds & Not tested & $46-47$ \\
VP 25628 (IGP) & P- and N-containing compounds & Not tested & $57-58$ \\
Disflamoll TP LXS 51064 (Lanxess) & Organophosphorous compound & Not tested & $32-33$ \\
Betol 39 T3 (Wöllner) & Alkali silicate & Not tested & $38-49$ \\
Betol 39 T3 (Wöllner) and catalyst & Alkali silicate and ammonium hydroxide & $28-29$ & $46-47$ \\
Slurry, non-commercial (Clariant) & Aluminum diethyl phosphinate & $31-32$ \\
\hline
\end{tabular}

Either $10 \%$ or $20 \%$ of the FR was applied, based on solids content and dry wood flour. All FR were provided in liquid form, except for zinc borate, which was provided in powder form and dissolved in water. Numbers in bold represent the FR with the highest LOI, which were selected for treatment of wood flour in combination with the polymer matrix 
$\mathrm{N}$-containing compounds (VP 25629 from IGP). This FR was investigated in detail regarding its thermal decomposition and mode of action in WPC by Seefeldt and Braun (2012a, b). It was shown that Disflamoll TP LXS 51064 acts mainly in the condensed phase by increasing the amount of residue formed by the wood part in the WPC. Additional flame dilution is achieved by the release of water, ammonia and carbon dioxide during the decomposition of the FR. Seefeldt and Braun (2012a, b) did not determine LOI values for wood particles treated with Disflamoll TP LXS 51064.

In summary, based on the results shown in Table 3, the two FR with the highest LOI were selected for compounding trials, i.e. Exolit AP 420 and Apyrol NCE Conc.

To select FR for the protection of the polymer matrix, PP was compounded together with several types of FR. The amount of FR used was 30\%, with the exception of magnesium hydroxide which was also used at $50 \%$ (wt) because it is well known that metal hydroxides need to be applied in high amounts to be effective in thermoplastics (Weil and Levchik 2016). During combustion, metal hydroxides serve to remove heat by releasing large amounts of water at the same temperature or below the temperature at which the decomposition of the polymer occurs. Thus, by absorbing heat, they slow down the polymer pyrolysis process. The generated water vapors dilute the combustible gases of polymer decomposition. Furthermore, a non-flammable layer on the surface of the material is developed which protects the substrate. Another benefit of metal hydroxides is their contribution to smoke suppression. The two most commonly used mineral flame retardants are aluminum trihydroxide (ATH) and magnesium dihydroxide (MDH) which was used in this project. The advantage of MDH is its higher decomposition temperature (approx. $340^{\circ} \mathrm{C}$ ) compared to ATH $\left(180-200{ }^{\circ} \mathrm{C}\right)$. APP was used in combination with PER and melamine to obtain an intumescent system. In this case, it is recommended to use a ratio of 3:1:1 for APP:PER:melamine. Intumescent flame retardants operate in the condensed phase, interrupting the self-sustained combustion of the polymer at its earliest stage (Kiliaris and Papaspyrides 2014). Generally, intumescent systems consist of three components: (1) an acid source, e.g., ammonium polyphosphate or melamine polyphosphate, (2) a carbonization agent, e.g., pentaerythrithol or starch, and (3) a blowing agent, e.g., melamine or urea. The development of a swollen char is the result of the interaction of these components. The acid source decomposes to a mineral acid that dehydrates the polyol to generate the carbon char mainly by a free radical process. The carbon char is foamed by non-flammable gases emitted during the degradation of the blowing agent.

The results for oxygen index and modified horizontal UL94-test of PP including FR are shown in Fig. 1. All formulations of this series reached classification $\mathrm{HB}$ according to DIN EN 60695-11-10 at a sample thickness of $4 \mathrm{~mm}$. The best four formulations showed LOI values between 33 and 35, and immediate extinguishing after withdrawal of the flame. Pure PP has an oxygen index of 18 (Horacek 2012). For LOI values of approximately 25 or higher, it is not possible to determine a horizontal burning rate because above this threshold, the polymers are self-extinguishing. Figure 1 shows that there is no correlation between LOI and the horizontal burning rate if LOI is 33 or lower. The most important conclusion from Fig. 1 is that if LOI is 33 or higher, the

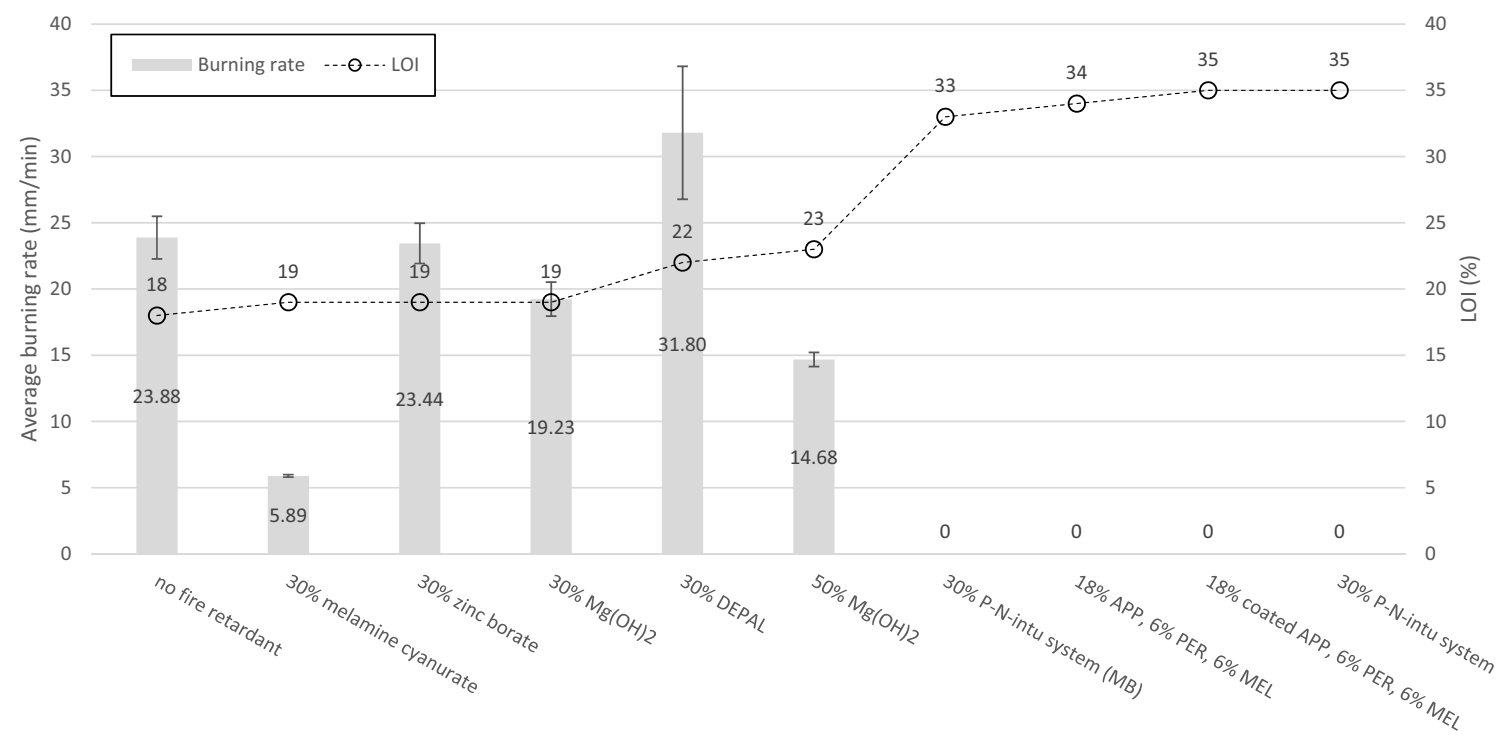

Fig. 1 Results for limiting oxygen index (LOI) and horizontal burning rate of various formulations based on polypropylene and fire-retardants (excluding wood flour). Ranking was done according to LOI 
horizontal burning rate is zero and hence, it is likely that V0-classification (obtained in the vertical setup) can also be obtained. Consequently, the four best formulations were also subjected to the vertical UL94-test. The vertical test showed that V0-classification could in fact be achieved for these formulations which consisted of intumescent APP-PERmelamine and P-N-systems. Compared to these intumescent systems, other FR such as melamine cyanurate, zinc borate, magnesium hydroxide and aluminum diethyl phosphinate (DEPAL) did not perform as well in the selected PP matrix under the conditions of the present experiments. This could be due to the fact that synergists were not used. The flame retardancy of PP and other polyolefins was reviewed by Weil and Levchik (2008) and Zhang and Horrocks (2003). They conclude that in general, char-promoting additives such as PER in the presence of APP, and its combination with adjuvants, for example zinc borate or borosiloxane, may improve fire properties and flammability. This is in line with the present results which confirmed the effectiveness of the APPPER-melamine combination for the PP used here.

PP systems based on metal hydroxide flame retardants such as aluminum trihydrate (ATH) and magnesium hydroxide have the general disadvantage that they require high FR loadings to achieve sufficient fire properties which in turn has a negative influence on mechanical properties. The required high loadings can be a problem in WPC where a high amount of filler is already present in the form of wood particles or fibres. In the present investigations, the vertical UL94 test was not performed for the formulations with magnesium hydroxide due to the relatively low oxygen index and higher horizontal burning rates compared to the APPPER-melamine and P-N-systems.

The PP compounds with $30 \%$ zinc borate showed a relatively low LOI of $19 \%$ which was the same as for $30 \%$ magnesium hydroxide. The LOI of zinc borate could probably be increased with the addition of synergists. Zinc borate shows the best synergistic effect in combination with metal hydroxides, and good synergism has also been observed in combination with antimony trioxide (Nikolaeva and Kärki 2011). In addition to fire retardancy, borates have additional advantages such as good smoke suppression, protection against fungi and insects, and low cost.

As mentioned above, the by-product from the aluminum diethyl phosphinate (DEPAL) production was also tested in PP (without any wood particles) but did not perform as well as the intumescent systems tested and was therefore not explored further. DEPAL is often used as halogen-free FR for polyamides, polyesters and thermoset resins. If used alone, it partly vaporizes and partly decomposes to volatile diethylphosphonic acid and aluminum phosphate residue (Hörold 2014). In a fire, a predominant gas phase action was observed but the material did not reach a V0 classification. If melamine polyphosphate (MPP) is used as synergist,
V0 can be achieved because of the reaction of MPP with phosphinate.

In summary, under the conditions of these trials, intumescent FR including the two types of APP tested, performed best to protect the polymer matrix (PP). The next step was then to combine the FR which worked best for wood flour (Exolit AP 420 and Apyrol NCE Conc.) with two of the best candidates for the polymer matrix. It was decided to use Exolit AP 422 and 462 for the polymer matrix to compare the differences between these types of APP, i.e. uncoated vs. coated APP. An uncoated APP may provide the advantage of improved polar interaction with the treated wood particles.

\subsection{Oxygen index (LOI) and UL 94 tests with compounds prepared using underwater or air granulation}

To determine the effects of granulation (underwater versus air), the compounds based on HDPE and PP (compare list in Table 1) were investigated. The differences between underwater and air granulation could be seen clearly for the PPbased compounds by visual observation. Due to the slower cooling and heat dissipation during air granulation, the granules tended to stick together, whereas the granules from underwater granulation were separated from each other. The granules based on PP were slim, rice-grain shaped while the granules based on HDPE were in the form of platelets or flakes. In general, the colour stability of the fire-retarded formulations with PP as matrix was higher than of the formulations with HDPE which had a greyish appearance.

All formulations based on HDPE and including FR reached LOI values between 26 and 30\%, indicating the self-extinguishing behaviour of the materials (Fig. 2). The reference without any FR reached a LOI value of $20-21 \%$. In most cases, LOI values of the formulations which were processed using air-granulation were slightly higher than of the formulations which were processed with underwater granulation.

The formulations based on PP (Fig. 3) displayed a slightly lower LOI compared to HDPE which was below the threshold for self-extinguishing materials. Here, LOI for formulations processed with underwater granulation were mostly higher than for those processed with air granulation. However, the differences in LOI between air and underwater granulation were not large in general.

Three formulations based on HDPE reached V0@4 mm classification. All of these formulations contained wood flour which was treated with Apyrol. Their respective counterparts without treated wood flour did not reach V0-classification which indicates that the wood flour treatment with Apyrol increased the fire-retardancy of the composites. Apyrol is a solution based on methylphosphonic acid in combination with urea. The combination of phosphorous 
35

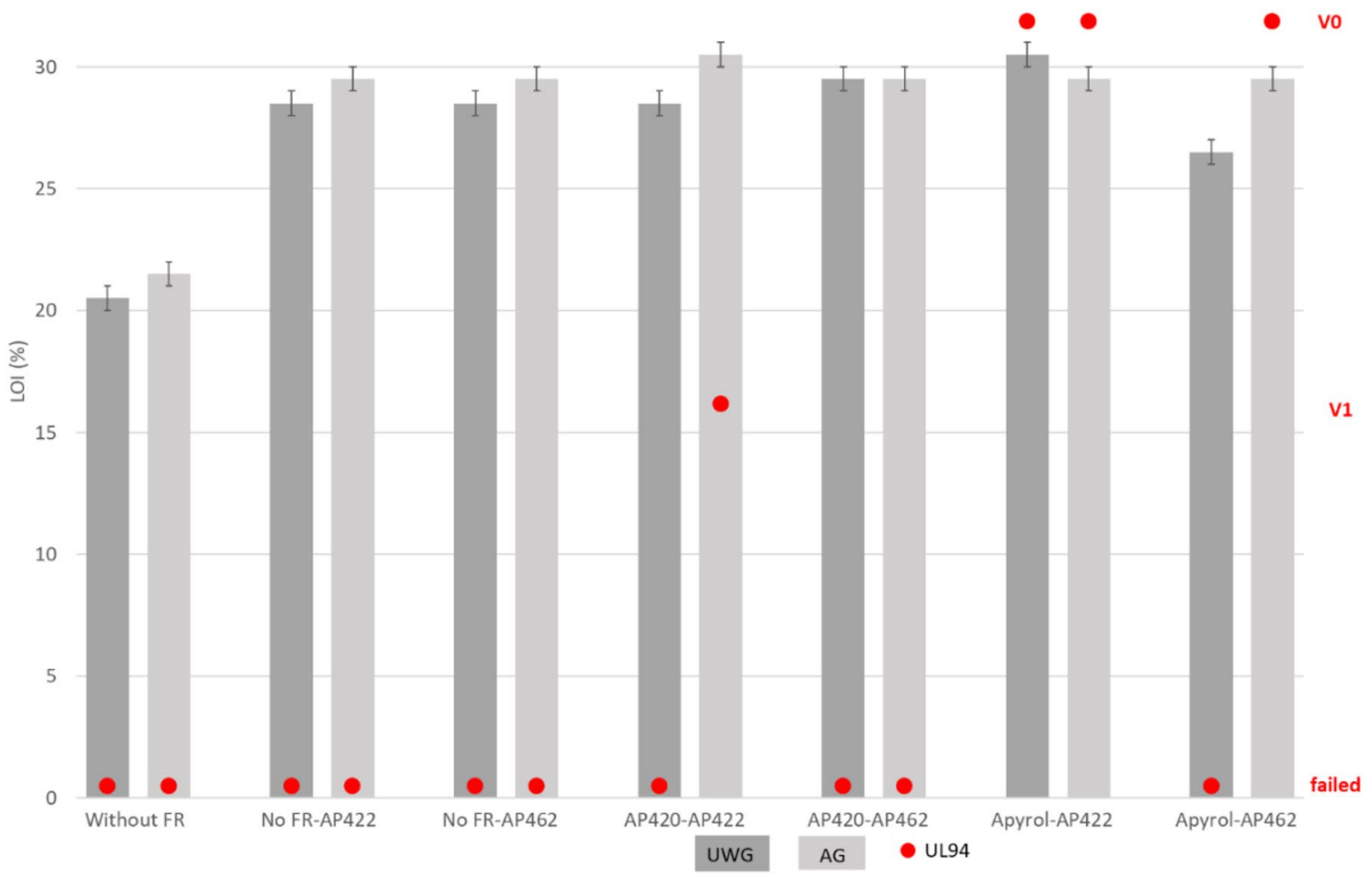

Fig. 2 Limiting oxygen index and UL94-classification of HDPE-based compounds

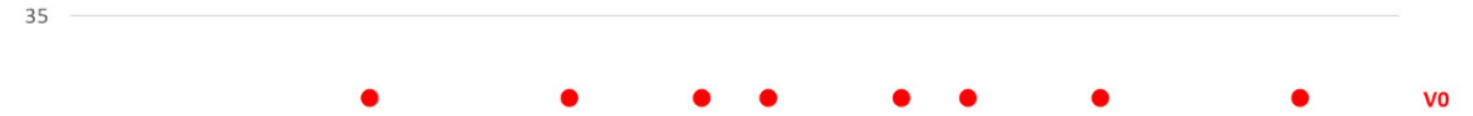

30

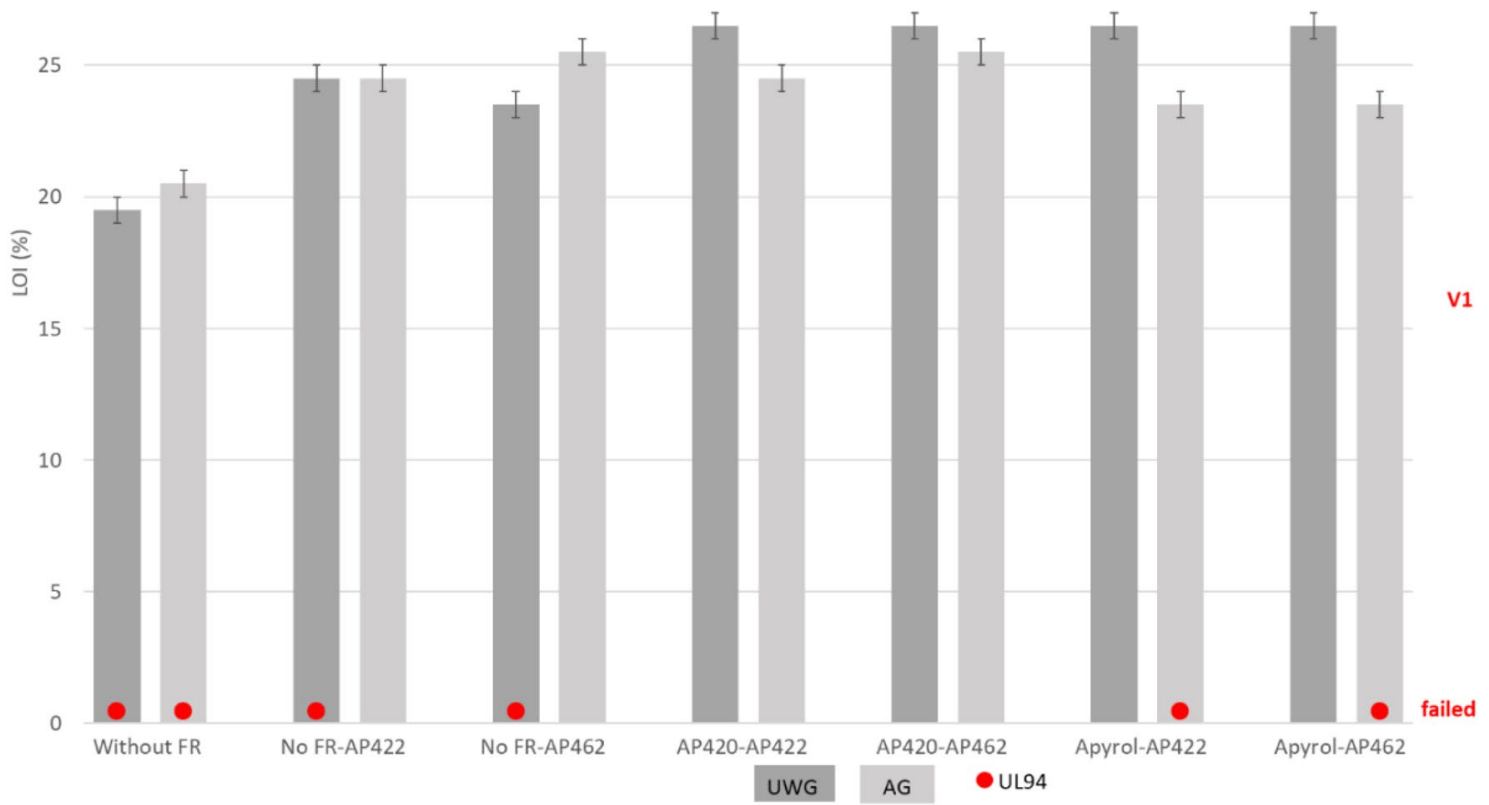

Fig. 3 Limiting oxygen index and UL94-classification of PP-based compounds 
and nitrogen as used in Apyrol usually creates a synergistic effect (Stark et al. 2009). When wood is treated with this synergistic combination, the retention of phosphorous in the char is caused by cross-linking of the cellulose during the process of pyrolysis by esterification with the dehydrating agents (Nikolaeva and Kärki 2011). Furthermore, addition of nitrogen compounds to phosphorous-containing compounds may stimulate the polycondensation of phosphoric acid to polyphosphoric acid. Polyphosphoric acid in turn can act as a thermal and oxygen barrier limiting access to the material surface since it creates a viscous fluid coating (Levan 1984).

Under the conditions of this study, the pre-treatment of wood flour with APP (AP420) was not successful to confer V0-classification to the composites with HDPE. In the best case, V1 classification could be obtained (AP420-AP422; air-granulation only). Ammonium polyphosphate, the ammonium salt of polyphosphoric acid, is decomposed into polyphosphoric acid and ammonia upon heating. Hence, an intumescent protection layer is formed which prevents the oxidation of the material and improves charring. It has also been reported that APP reduces smoke production and provides resistance to flame spread (Stark et al. 2010, 2009).

In case of the PP-based formulations, a larger number of V0-classifications was obtained. Here, eight out of fourteen formulations reached V0@4 mm. Half of these eight formulations were processed with underwater granulation and half with air granulation. In contrast to the formulations based on HDPE, V0-classification could be achieved even with untreated wood flour for two formulations (no FR-AP422 and no FR-AP462; both processed by air granulation). In addition, V0-classification for the PP-based formulations was obtained with a lower LOI compared to the HDPEbased formulations. This shows that there is no correlation between the results of the LOI and UL94-test. Whereas the LOI test is used to determine the minimum concentration of oxygen, in admixture with nitrogen, that will support combustion of small vertical test specimens, in the UL94 test, the flammability rating of the material is determined. The observed differences between the UL94-results for PP- and HDPE-based WPC could be related to the melting points of the base polymers. The melting point of PP is higher than for HDPE, hence, in the case of PP, it is more energy required to heat up the same amount of polymer. In addition, differences in viscosity may play a role in flammability characteristics of the composites. Borysiak and Paukszta (2006) investigated the flammability of WPC based on PP with different MFI. Using cone calorimeter measurements, they determined that PP composites with higher MFI values have longer time to ignition, lower HRR and longer total burning time. These findings were interpreted in terms of varying degrees of wettability of wood particles by the PP matrices. One aspect that merits further investigation is why for the PP-based formulations with untreated wood flour and with APP for the polymer matrix, only air granulation resulted in V0-classification. The corresponding formulations processed with underwater granulation did not pass the test. In the cases where the wood flour was treated with Apyrol, the opposite occurred: here, formulations processed with underwater granulation reached $\mathrm{V} 0$ whereas the formulations processed with air granulation failed. The reason for this is not understood yet. In the case of air granulation, leaching of the FR can be excluded. In addition, there were no differences in the moisture content of the treated wood flour since all batches were dried before compounding. Hence, it is unlikely that wood moisture was locked up in the compounds during processing which could not be removed later. In addition, compounds were dried again before injection-moulding and conditioned before LOI and UL94-tests. Further investigations using the cone calorimeter and crystallinity measurements may provide additional insight. In any case, at this stage it is an important conclusion that processing compounds with underwater and air granulation can lead to different outcomes in small-scale fire tests such as the UL94. This has important implications for the choice of processing method for fire-retarded composite materials and for formulation development of such materials in general.

\subsection{Leaching of fire-retardants during processing}

To determine the amount of fire-retardant which may have leached during underwater granulation, the process water was collected and analysed for phosphorus content. For treatment of the wood flour, APP (Exolit AP 420) and a formulation based on methyl phosphonic acid in combination with carbamoyl-guanidine amidino urea salt (Apyrol NCE CONC.) were used. Exolit AP 420 contains 12.5-13.5\% phosphorus in a $45 \%$ solution. The phosphorus content of Apyrol NCE CONC. is not disclosed and was calculated as $8 \%$, based on the molar mass proportion of $\mathrm{P}(16 \%)$ in the main components methyl phosphonic acid and carbamoylguanidine amidino urea salt (CAS 84402-58-4; $\mathrm{CH}_{5} \mathrm{O}_{3} \mathrm{P}$ and $\mathrm{C}_{2} \mathrm{H}_{6} \mathrm{~N}_{4} \mathrm{O}$ ) and the solids content (50\%) of the solution. The amount of phosphorus in the two APP types used for protection of the thermoplastics was 32\% (Exolit AP 422) and 30\% (Exolit AP 462).

The maximum possible concentration of $\mathrm{P}$ for the formulations in the process water was determined according to the scheme shown in Table 4. The calculation is shown for the two formulations which contain the theoretically highest amount of APP, i.e., AP420-AP422. First of all, it was necessary to determine the amount of compound in contact with process water. This was done by weighing the amount of compound which was produced before the sampling process started, and subtracting this from the amount of compound after the sampling was finished. Hence, the amount 
of compound in contact with process water was different for each formulation. For the two formulations shown in Table 4, the numbers were $3.77 \mathrm{~kg}$ and $3.59 \mathrm{~kg}$, respectively. Using the calculated maximum amount of leached $\mathrm{P}$ and the total amount of process water, the maximum possible $\mathrm{P}$ concentration in the process water was calculated $(1455.79 \mathrm{mg} / \mathrm{l}$ for the HDPE-based formulation and $1387.71 \mathrm{mg} / \mathrm{l}$ for the PP-based formulation). The conversion of the maximum possible concentration $(\mathrm{mg} / \mathrm{l})$ of leached $\mathrm{P}$ into wt.- $\%$ is shown in Table 5. The calculated amounts of leached $P$ in the process water were $2.28 \mathrm{wt} \%$ for the HDPE-based formulation and $0.84 \mathrm{wt} \%$ for the PP-based formulation.

The results of the ICP-OES measurements show that the $\mathrm{P}$ concentrations of the process water (leachate) collected during underwater granulation were higher for the HDPEbased formulations compared to the PP-based formulations (Fig. 4). The highest amount of leached P (36 mg/l) was determined for formulation AP420-AP422 based on HDPE. The same formulation based on PP released only $12 \mathrm{mg} / \mathrm{l}$ phosphorus, i.e., only one third of the amount. The reference formulations without any FR were also analyzed. Here, small amounts of $\mathrm{P}(0.34 \mathrm{mg} / \mathrm{l}$ for the HDPE-based formulation and $2.8 \mathrm{mg} / \mathrm{l}$ for the PP-based formulation; results not shown) were detected in the process water which may originate from any of the other components. These amounts were subtracted from the results for the formulations including FR when calculating the amount of $\mathrm{P}$ leaching in wt $\%$ (Table 5; Fig. 4). The references without any FR did not show any leaching of $\mathrm{P}$ and hence, are not shown in Fig. 4 because here, only the leaching of $\mathrm{P}$ from the FR was considered. Leaching of $\mathrm{P}$ was higher for the HDPE-based formulations (up to $2.5 \%$ ) compared to the PP-based formulations (up to $1.7 \%$ ). This could be due to the higher polarity of PP compared to HDPE which may result in stronger polar interaction of PP-based compounds with the FR compared to the HDPE-based compounds. The polar part of the surface energy is in the order of $0.3-1.3 \mathrm{~mJ} / \mathrm{m}^{2}$ for $\mathrm{PP}$ and in the order of $0-0.7 \mathrm{~mJ} / \mathrm{m}^{2}$ for HDPE (Anonymous 2020). If the polar part of the surface energy is higher than $1 \mathrm{~mJ} / \mathrm{m}^{2}$, a polymer is considered as polar; if it is smaller, a polymer is considered as non-polar. In most formulations with FRtreated wood flour, the amount of P leaching was higher

Table 4 Calculation of maximum possible concentration of phosphorus leached during underwater granulation for formulation AP420-AP422 with HDPE and PP matrix

\begin{tabular}{|c|c|c|c|c|c|c|c|c|c|}
\hline Formulation & APP & $\begin{array}{l}\text { Amount of } \\
\text { P in APP } \\
(\%)\end{array}$ & $\begin{array}{l}\text { Amount } \\
\text { of APP in } \\
\text { formulation } \\
(\%)\end{array}$ & $\begin{array}{l}\text { Compound } \\
\text { produced } \\
\text { at start of } \\
\text { leachate col- } \\
\text { lection }(\mathrm{kg})\end{array}$ & $\begin{array}{l}\text { Compound } \\
\text { produced } \\
\text { at end of } \\
\text { leachate col- } \\
\text { lection }(\mathrm{kg})\end{array}$ & $\begin{array}{l}\text { Amount of } \\
\text { compound } \\
\text { in contact } \\
\text { with process } \\
\text { water }(\mathrm{kg})\end{array}$ & $\begin{array}{l}\text { Calculated } \\
\text { maximum } \\
\text { amount of } \\
\text { leached } \mathrm{P} \\
(\mathrm{kg})\end{array}$ & $\begin{array}{l}\text { Total } \\
\text { amount } \\
\text { of process } \\
\text { water (1) }\end{array}$ & $\begin{array}{l}\text { Calculated } \\
\text { max. possible } \\
\text { P conc. in } \\
\text { process water } \\
(\mathrm{mg} / \mathrm{l})\end{array}$ \\
\hline \multirow[t]{2}{*}{ HDPE } & $\begin{array}{l}\text { Added dur- } \\
\text { ing com- } \\
\text { pounding }\end{array}$ & 32.0 & 16 & 1.15 & 4.92 & 3.77 & $* 0.193$ & 147 & 1312.93 \\
\hline & $\begin{array}{l}\text { Added to } \\
\text { wood }\end{array}$ & 13.5 & 4.2 & 1.15 & 4.92 & 3.77 & $* * 0.021$ & 147 & 142.86 \\
\hline Total & & & & & & & & & 1455.79 \\
\hline \multirow[t]{2}{*}{ PP } & $\begin{array}{l}\text { Added dur- } \\
\text { ing com- } \\
\text { pounding }\end{array}$ & 32.0 & 16 & 0.89 & 4.48 & 3.59 & 0.183 & 147 & 1249.35 \\
\hline & $\begin{array}{l}\text { Added to } \\
\text { wood }\end{array}$ & 13.5 & 4.2 & 0.89 & 4.48 & 3.59 & 0.020 & 147 & 138.36 \\
\hline Total & & & & & & & & & 1387.71 \\
\hline
\end{tabular}

*Calculated as: $3.77 \mathrm{~kg}$ multiplied by amount of APP in formulation (0.16) and amount of P in APP (0.32)

**Calculated as: $3.77 \mathrm{~kg}$ multiplied by amount of APP added to wood (0.042) and amount of P in APP (0.135)

Table 5 Calculation of leached amount of phosphorus during underwater granulation for formulation AP420-AP422 with HDPE and PP matrix

\begin{tabular}{llllll}
\hline Formulation & $\begin{array}{l}\text { Calculated max. possible } \\
\text { P conc. in process water } \\
(\mathrm{mg} / \mathrm{l})\end{array}$ & $\begin{array}{l}\text { Measured P conc. of } \\
\text { formulation in process } \\
\text { water }(\mathrm{mg} / \mathrm{l})\end{array}$ & $\begin{array}{l}\text { Measured P conc. of } \\
\text { reference in process } \\
\text { water }(\mathrm{mg} / \mathrm{l})\end{array}$ & $\begin{array}{l}\text { P conc. of formulation } \\
\text { minus P conc. of refer- } \\
\text { ence (mg/l) }\end{array}$ & $\begin{array}{l}\text { Calculated amount of } \\
\text { leached P in process } \\
\text { water (wt\%) }\end{array}$ \\
\hline HDPE & 1455.79 & 36 & 2.80 & 33.20 & $\begin{array}{c}2.28(\text { note: } 1455.79 \\
\text { equals } 100 \%)\end{array}$ \\
PP & 1387.71 & 12 & 0.34 & 11.66 & $\begin{array}{c}0.84(\text { note: } 1387.71 \\
\text { equals } 100 \%)\end{array}$ \\
\hline
\end{tabular}


Fig. 4 Amount of phosphorus (wt\%) in process water from underwater granulation. For composition of formulations, see Table 1 . Only leached P from the FR was considered, hence, no leaching from the two reference formulations is shown. Error bars shown represent the standard deviation of the method (1.3\%)

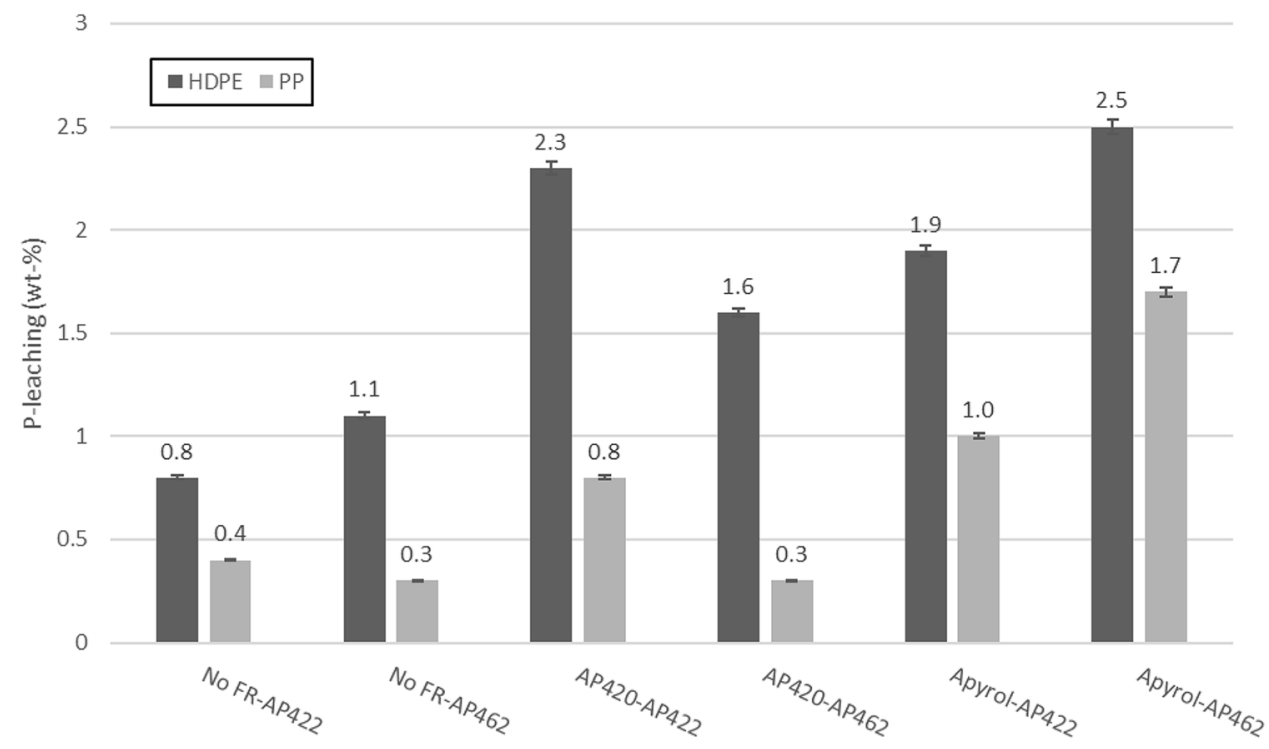

Table 6 UL94-classification, LOI and colour changes of selected formulations after $300 \mathrm{~h}$ xenon weathering (b.w. means before weathering, a.w. means after weathering)

\begin{tabular}{|c|c|c|c|c|c|c|c|c|c|}
\hline Formulation & UL 94 b. w. & UL 94 a. w. & LOI b. w. & LOI a. w. & $\Delta L^{*}$ & $\Delta a^{*}$ & $\Delta b^{*}$ & $\Delta E^{*}$ & $\Delta G$ \\
\hline HDPE: Apyrol-AP422 (UWG) & V0 & Not passed & 30 & 24 & 12.4 & 1.0 & 1.0 & 12.5 & -5.0 \\
\hline HDPE: Apyrol-AP422 (AG) & V0 & Not passed & 29 & 27 & 14.0 & 1.3 & 0.9 & 14.1 & -3.3 \\
\hline PP: AP420-AP422 (UWG) & V0 & V0 & 26 & 25 & 18.2 & 1.1 & 1.4 & 18.4 & -11.7 \\
\hline PP: AP420-AP422 (AG) & V0 & V0 & 24 & 24 & 15.8 & 1.6 & 1.8 & 15.9 & -12.5 \\
\hline PP: AP420-AP462 (UWG) & V0 & V0 & 26 & 26 & 20.9 & 0.5 & 0.7 & 20.9 & -12.3 \\
\hline PP: AP420-AP462 (AG) & V0 & V0 & 25 & 25 & 23.2 & 0.8 & 0.8 & 23.2 & -11.3 \\
\hline
\end{tabular}

For composition of formulations, see Table 1

compared to when untreated wood flour was used which can be expected. In general, leaching of $P$ from the process water was low with values below $3 \mathrm{wt} \%$. Regarding the type of APP used for the polymer matrix (uncoated AP 422 versus coated AP 462), no clear tendency could be observed for the resistance of the FR against leaching during processing. However, there may be differences during longterm exposure of the materials to water. Wang et al. (2016) investigated the differences in water solubility of a microencapsulated APP versus an uncoated APP. They determined decreased water solubility of APP after microencapsulation.

\subsection{UL94, LOI and colour changes after xenon weathering}

The three formulations which were processed using underwater granulation and which achieved V0-classification while displaying the lowest leaching of phosphorous were Apyrol-AP422 (HDPE), AP420-AP422 (PP) and AP420AP462 (PP). These formulations were subjected to artificial weathering in a xenon device for $300 \mathrm{~h}$ and then tested again to determine UL94-classification, LOI and colour changes. For comparison, the same formulations which had been processed using air granulation were also tested. The results are shown in Table 6. While formulation Apyrol-AP422 (HDPE) achieved V0 before weathering and failed after weathering, all formulations based on PP remained at the V0 classification after $300 \mathrm{~h}$ weathering. Because in the weathering test, different FR were used for the wood particles (Apyrol for the compounds with HDPE and AP420 for the compounds with PP), it is not possible to draw general conclusions. It can only be concluded that during short term weathering for $300 \mathrm{~h}$ in a xenon device, the compounds based on PP and with APP for the wood particles as well as for the matrix kept their UL94 classification. More long-term studies are needed to investigate the long-term durability behavior of WPC with FR. The $300 \mathrm{~h}$ duration is a requirement in DIN EN 15534, parts 4 and 5, if xenon weathering according to EN ISO 4892-2A is applied. In case of artificial weathering, hydrolysis of APP may occur and result in reduced fire retardancy as the formation of the intumescent network is disturbed already after exposure with an incident energy of 
$210 \mathrm{~kJ} \mathrm{~cm}^{-2}$, a value which corresponds to less than 1 year of outside use in mid-Europe (Pfaendner 2014).

Colour changes $(\Delta \mathrm{E})$ of the tested formulations were high, with values ranging between 12.5 and 23.2. Better results in terms of colour stability and gloss $(\Delta G)$ were obtained for the HDPE-based formulation compared to the PP-based formulations. The values for oxygen index were slightly reduced for the HDPE-formulation and remained at the same level as before weathering for the PP-based formulations.

Little information is available in the scientific literature regarding the durability of FR treatments for WPC. Garcia et al. (2009) determined colour changes $(\Delta \mathrm{E})$ for WPC based on HDPE and with APP as FR which were in the range of 22-26 after $600 \mathrm{~h}$ of weathering which is much higher than the values for colour change determined here for the HDPEbased formulations. However, differences in processing, base polymer, additivation and type of weathering (Garcia et al. used QUV weathering) have to be considered. The fire performance after weathering was not investigated.

Color changes after weathering of WPC based on PP and with different FR (aluminum trihydrate, zinc borate, melamine, graphite, titanium dioxide) were investigated by Turku and Kärki (2016). Duration of the weathering was 1000 h, and samples were subjected to weathering under a xenonarc lamp source. FTIR analysis revealed that the FR did not influence the photo-oxidation mechanism of the composite. Surprisingly, it was found that FR-loaded samples showed smaller color change compared to unfilled ones.

Some recently developed flame retardants combine flame retardancy and light stabilizer functionality (Pfaendner
2014), however, the photooxidative stabilization of flameretarded "green" composites is a complex field as the polymer, FR system, additives (processing stabilizers, antioxidants, light stabilizers, etc.) and filler have to be considered together.

\subsection{Thermogravimetric analysis (TGA)}

TGA was performed with compounds AP420-AP422 (HDPE and PP matrix) which had been processed using either air or underwater granulation. For comparison, the reference compound without FR was analyzed. The results are shown in Figs. 5, 6. Some differences between the compounds processed with underwater and air granulation are visible, but the differences between fire-retarded and non-fire-retarded formulations are more pronounced. Up to a temperature of approximately $200{ }^{\circ} \mathrm{C}$, little weight loss occurred. For the compounds based on HDPE, in the temperature range between 200 and $320^{\circ} \mathrm{C}$, the fire-retarded formulation which contained wood flour pre-treated with APP plus APP for the polymer matrix showed less thermal stability than the unprotected formulation. This can be attributed to the formation of polyphosphoric acid which catalyzes the degradation of the wood flour (Abu Bakar et al. 2010). From $320{ }^{\circ} \mathrm{C}$ onwards, thermal stability of the fire-retarded formulation was higher compared to the unprotected one. Mass loss of the unprotected formulation occurred faster and resulted in lower residue ( $2.56 \%$ for the compound prepared using air granulation and $2.75 \%$ for the compound prepared using underwater granulation). The APP used for protection of the polymer matrix (Exolit AP 422) begins to degrade at

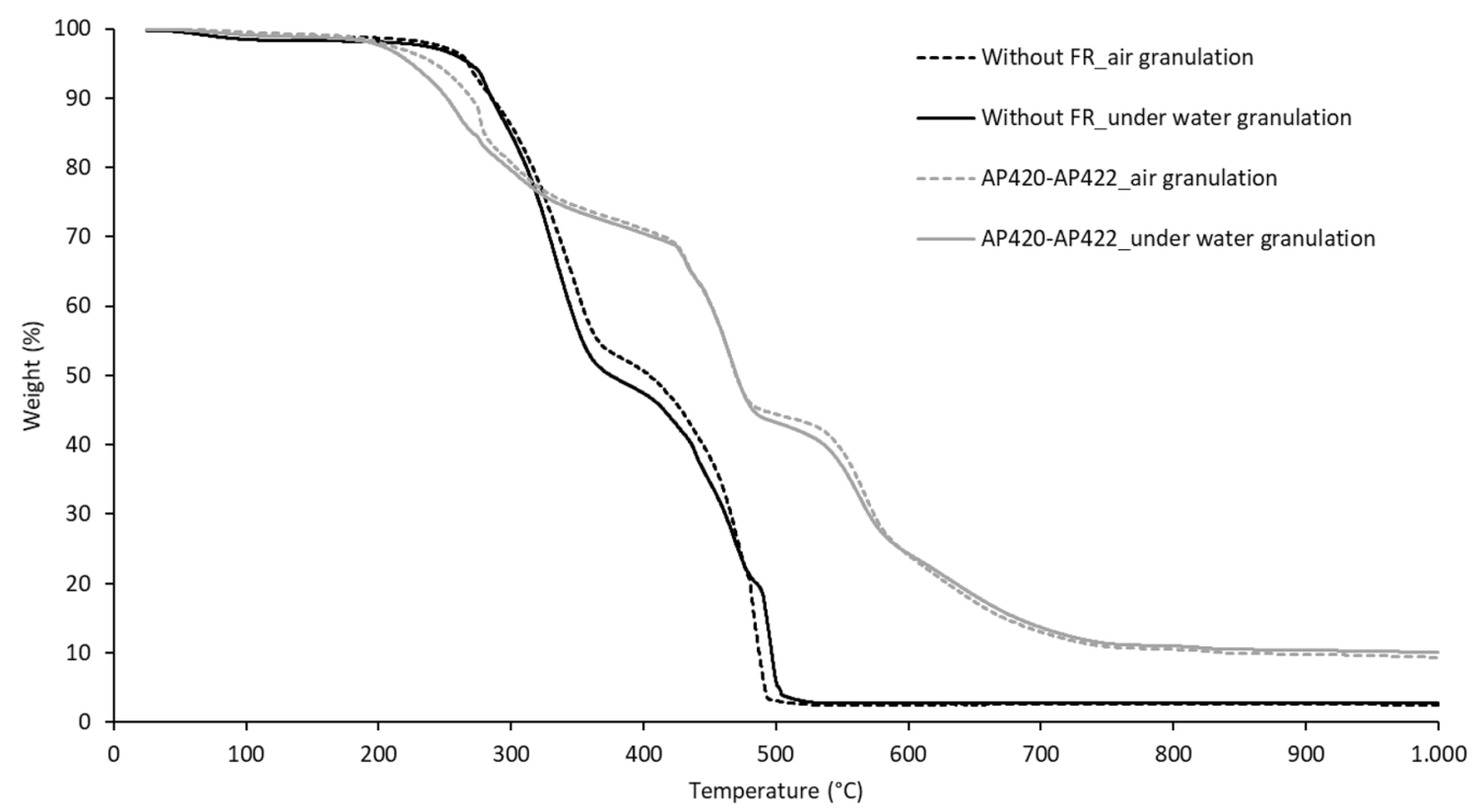

Fig. 5 TGA of HDPE-based compounds without any fire-retardant and with pre-treated wood flour plus APP 


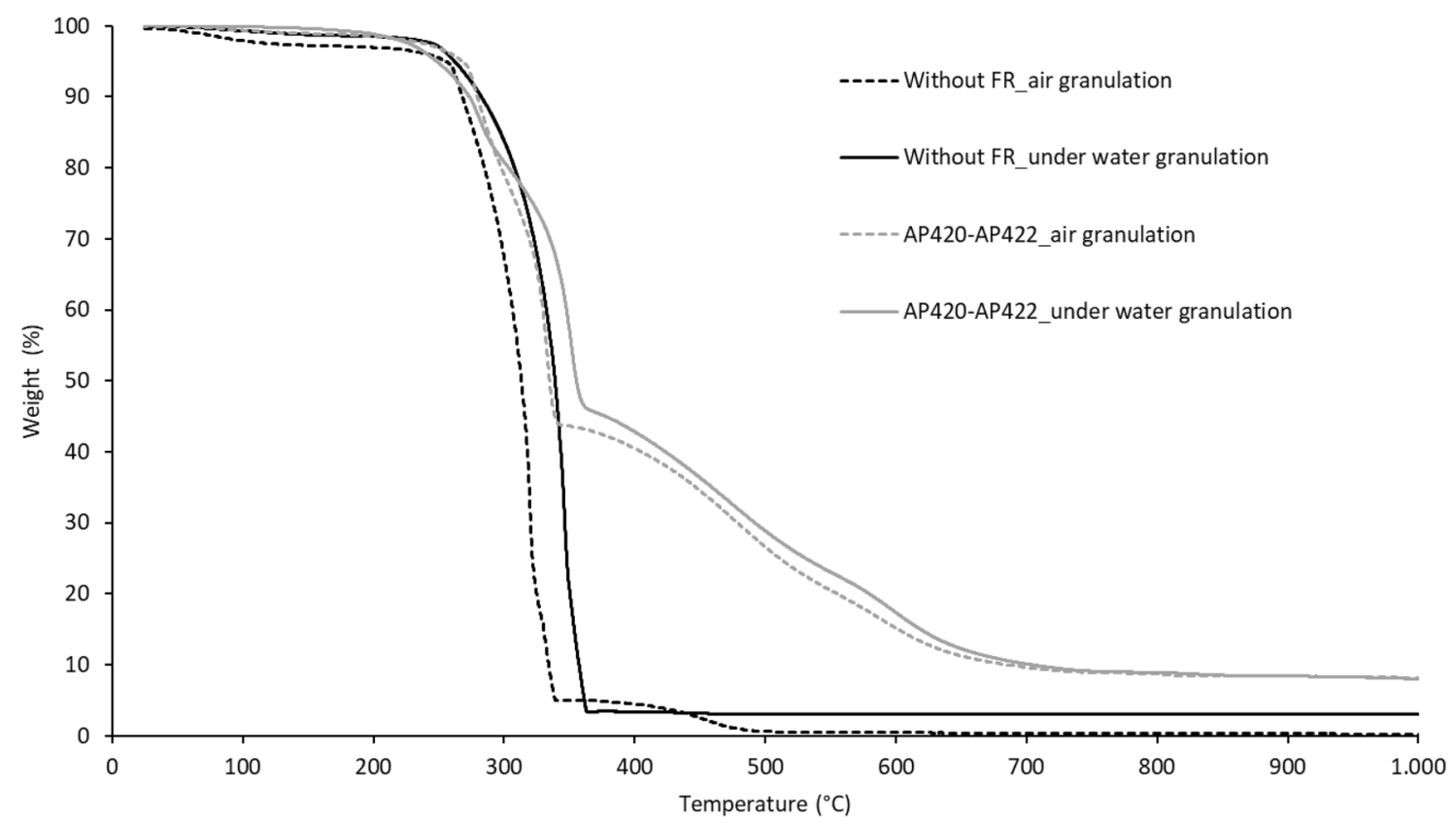

Fig. 6 TGA of PP-based compounds without any fire-retardant and with pre-treated wood flour plus APP

$275^{\circ} \mathrm{C}$, according to the technical data sheet. APP begins to decompose into polyphosphoric acid and ammonia. Polyphosphoric acid acts as a char-former and a char-phosphate insulation layer is formed on the wood particle surfaces. Approximately $20 \%$ weight loss of the Exolit AP 422 is reached at $550{ }^{\circ} \mathrm{C}$, according to the technical data sheet.

Between 400 and $600{ }^{\circ} \mathrm{C}$, for the fire-retarded compound based on HDPE, two steps are visible in the curves, one between 462 and $471{ }^{\circ} \mathrm{C}$, and another one between 562 and $569{ }^{\circ} \mathrm{C}$. For the unprotected formulation, there is only one steep degradation step during this temperature range. Final residues of the fire-retarded formulation (10.68\% with air granulation and $11.23 \%$ with underwater granulation) were more than three times higher than of the non-fire-retarded compounds. Mass loss of the unprotected formulation was completed at $500{ }^{\circ} \mathrm{C}$ whereas the protected formulation continued to show mass loss up to a temperature of $750{ }^{\circ} \mathrm{C}$.

Figure 6 shows the TGA curves for the PP-based compounds. Here, higher thermal stability up to $300{ }^{\circ} \mathrm{C}$ of unprotected compounds was not visible. For the PP-based formulations, the curves show less steps compared to the HDPE-based compounds. The highest mass loss rate was obtained between 319 and $357^{\circ} \mathrm{C}$. During this temperature range, mass loss of the unprotected formulation was as high as $95-97 \%$. In comparison, the fire-retarded formulations displayed significantly lower mass loss rate. From $350{ }^{\circ} \mathrm{C}$ onwards, stabilization of the fire-retarded formulations can be clearly seen in the curves. Final residues of the protected formulations $(8.44 \%$ with under water granulation and $8.90 \%$ with air granulation) were much higher compared to the unprotected formulations (3.41\% and $0.60 \%)$. As was seen with the HDPE-based compounds, differences in thermal stability and mass loss rates were larger between unprotected and protected compounds compared to differences related to the type of granulation.

\subsection{Tensile strength tests, water uptake and swelling of composites}

The effects of the FR on tensile strength of the composites as well as differences between underwater and air granulation are shown in Figs. 7, 8. In general, tensile strength was not reduced due to the presence of the FR, and in some cases even increased. Only when underwater granulation was used to process HDPE-based compounds, there was a reduction in tensile strength from $35.8 \mathrm{~N} / \mathrm{mm}^{2}$ to values between 28.4 and $31.3 \mathrm{~N} / \mathrm{mm}^{2}$. This amounts to a maximum reduction of $21 \%$ in tensile strength. It has to be considered that in the reference formulations without any FR, 58\% of wood particles were included whereas in the formulations which contained FR, $42 \%$ of wood particles were used. However, the total amount of filler (wood particles or combination of wood particles and FR) was identical for all formulations. It appears that the bonding between wood particles, polymer matrix and coupling agent was not affected by the presence of the FR in the formulations, with the exception of the HDPE-based compounds processed with underwater granulation. It is possible that the processing conditions affected the resulting crystallinity of the polymer matrices. Bouafif et al. (2009) showed that the addition of wood particles to 


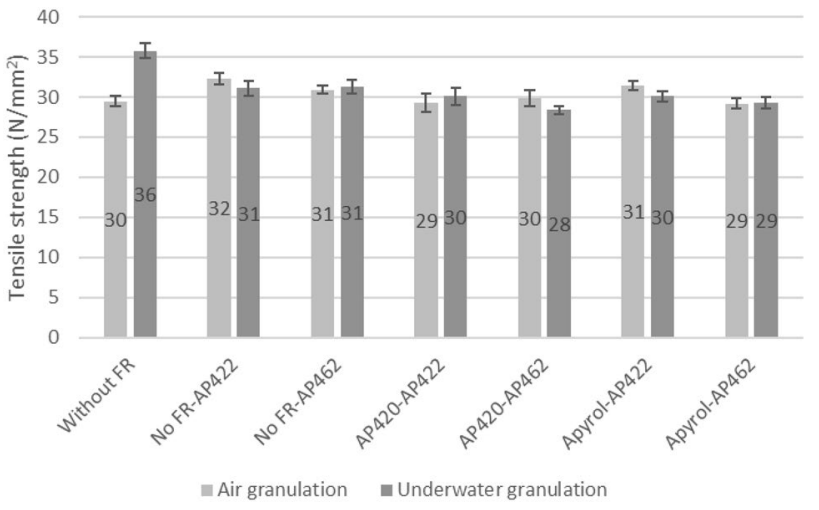

Fig. 7 Tensile strength of formulations based on HDPE (Table 1)

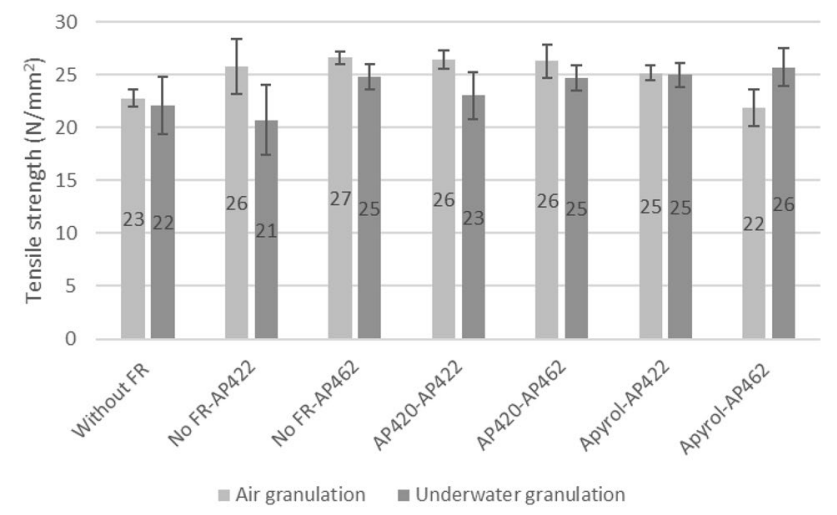

Fig. 8 Tensile strength of formulations based on PP (Table 1)

HDPE increased the crystallinity of the matrix which is due to the nucleating ability of wood particles in the crystallization of HDPE. The presence of the FR may also have an influence on the crystallinity of the HDPE. Crystallinity depends on processing parameters such as the crystallization temperature, cooling rate, nucleation density, annealing time, and fiber type (Bouafif et al. 2009). The crystallinity in semicrystalline polymers such as $\mathrm{PE}$ and $\mathrm{PP}$ is a major factor affecting their strength properties. The higher the degree of crystallization, the stronger and stiffer a moulded part may be but also the more brittle (Ehrenstein et al. 2003).

Tensile strength of the PP-based formulations was generally lower than of the HDPE-based formulations. This may partially be due to the type and shape of PP used. The HDPE was provided in powder form whereas the PP was provided in pellet form. Polymer in powder form can potentially be mixed better with wood flour, resulting in a more homogeneous distribution of the wood flour in the polymer and potentially, in higher strength. Overall, air granulation appeared to result in slightly higher tensile strength, with the exception of formulation Apyrol-AP462 (PP). The use of the FR did not result in lower tensile strength. On the contrary, in most cases, tensile strength was increased when FR was included.

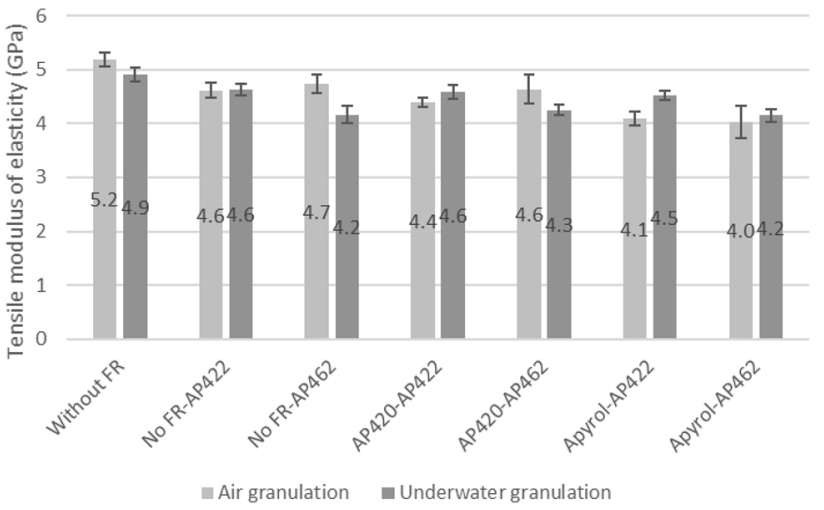

Fig. 9 Tensile modulus of elasticity of formulations based on HDPE (Table 1)

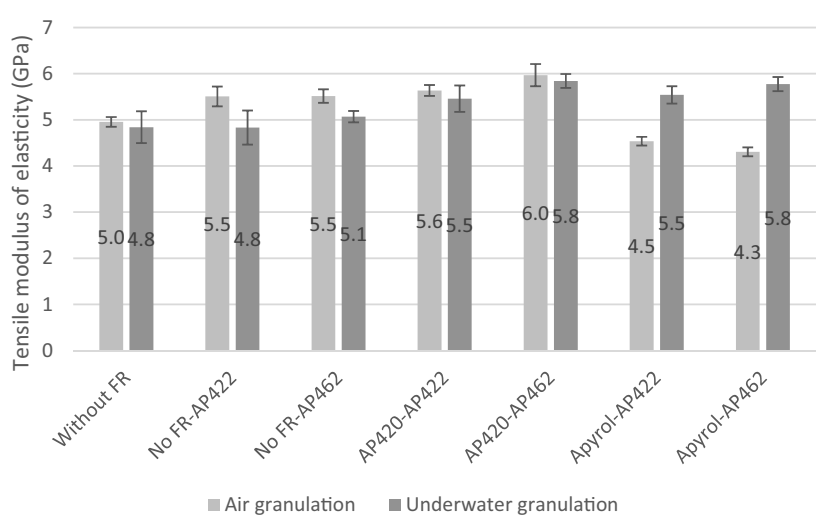

Fig. 10 Tensile modulus of elasticity of formulations based on PP (Table 1)

There was no difference in the tensile strength of PP-based formulations without FR when processed either with air or underwater granulation.

Regarding the tensile modulus of elasticity, different trends for the HDPE- and PP-based formulations were observed (Figs. 9, 10). For the HDPE-based formulations, the tensile MOE was reduced by up to $22 \%$ when a FR was included (Apyrol-AP462; air-granulation). In the formulations with FR, the FR probably interfered with the coupling agent resulting in a decrease in modulus. In addition, in the formulation without FR, a higher amount of wood flour was present which was available for bonding with the polymer via the coupling agent. In general, tensile MOE of HDPEbased formulations was between 4 and 5.2 GPa. For the PPbased formulations, except for two formulations, the tensile MOE increased with the addition of the FR.

Yin et al. (2018) determined the mechanical performance of injection-moulded, PP-based WPC samples with different FR combinations. In their formulations, either $30 \%$ wood filler (reference without FR) or 50\% filler (formulations with 
FR, composed of $30 \%$ wood filler plus $20 \%$ FR) were used. Hence, it is difficult to evaluate the effects of the FR. APP was used in combination with expandable graphite or red phosphorus. Under the conditions of the study by Yin et al., the combination of APP and red phosphorus retained the original flexural strength and increased flexural modulus, but Charpy impact strength was reduced significantly. In contrast, Stark et al. (2010) reported that APP had a negative effect on mechanical properties, however, in this case, polyethylene served as matrix.

Swelling and water uptake of the composites based on PP as matrix after 28 days of cold water immersion are shown in Figs. 11, 12. The reference formulation without any FR contained 58\% wood particles and 33\% PP (Table 1). When FR were included for the matrix, the amount of wood particles was reduced to $42 \%$. Compared to the reference without any FR, the compounds with $16 \%$ of APP for the PP matrix and with untreated wood particles showed increased values for swelling and water uptake. For example, in the case of the compounds made with underwater granulation, water uptake of the reference was about $6 \%$, compared to approximately $8-9 \%$ for the compounds with APP for the matrix. This increase in water uptake can be attributed to the hygroscopicity and moisture sensitivity of the APP (Wang et al. 2016). However, when the wood particles are pre-treated with FR (Exolit AP 420 or Apyrol NCE) and simultaneouly, APP is added during compounding, swelling and water uptake of the composite are reduced compared to when APP is added during compounding only. In this case, it is thought that the pre-treatment of the wood particles with the FR contributes to esterification of the wood particles and consequently, the hydroxyl groups may be blocked and water uptake is reduced. Hence, the wood particle pre-treatment may have a beneficial effect regarding water uptake and swelling. The wood flour pre-treatment appears to partially counteract the negative effect of the APP addition during compounding. This was also observed for the formulations

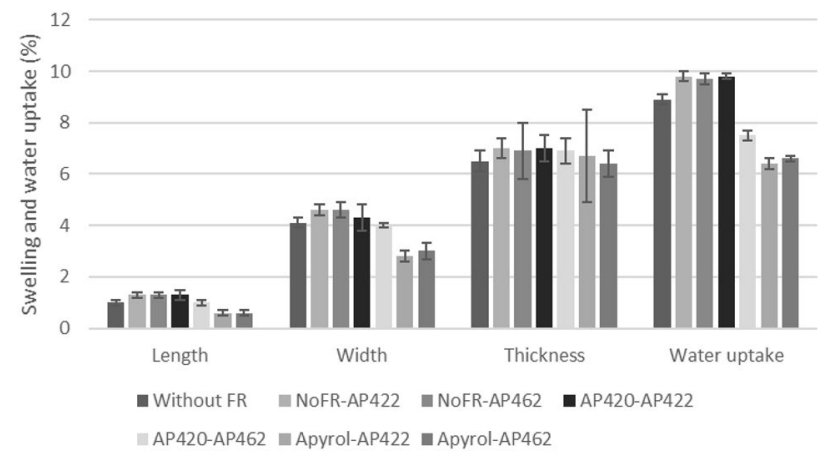

Fig. 11 Swelling and water uptake of PP-formulations (Table 1) after 28 days of cold-water immersion. Compounds were processed with air granulation

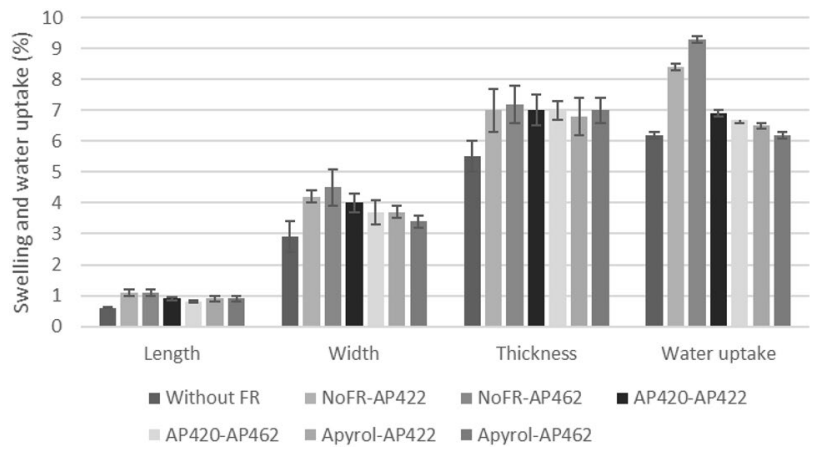

Fig. 12 Swelling and water uptake of PP-formulations (Table 1) after 28 days of cold-water immersion. Compounds were processed with underwater granulation

processed with air granulation, except for one formulation (AP420-AP422). Similar benefits for the use of modified wood flour in WPC were reported by Hämäläinen and Kärki (2014) who used phosphate-based FR solutions and a melamine formaldehyde resin for wood flour modification.

Another possible explanation for the observed reduced water uptake of compounds with pre-treated wood particles could be thermal degradation of the FR-treated wood particles. Upon heating, the APP on the wood particles can degrade into polyphosphoric acid which catalyzes the degradation of cellulose (Abu Bakar al. 2010). The result would be particles which are less hydrophilic, similar to heattreated wood particles. Butylina et al. (2011) have shown that WPC with heat-treated wood particles display lower water absorption compared to WPC with untreated wood.

In terms of water uptake and swelling, the most important conclusion is that it is better to use a wood particle pre-treatment plus APP for the matrix than just APP for the matrix. Since in this series, no formulation with pre-treated wood particles and without APP for the matrix was included, further experiments would be required to analyze the effects of the wood pre-treatment alone on swelling and water uptake of the composites. However, in practical terms, it does not appear to be useful to leave out the FR for the matrix if good reaction-to-fire performance of the composite is desired.

\subsection{Single-burning item (SBI) tests}

For the SBI test, formulation Apyrol-AP422 (HDPE-based) was chosen, based on the V0-classification (UL 94 test) achieved with air as well as underwater granulation, and due to the fact that the industrial WPC profile extrusion line used was set-up for HDPE as polymer matrix. For comparison, the corresponding formulation with untreated wood flour was chosen for the SBI test. In both formulations, APP was used to protect the polymer matrix. 
Before the SBI tests were performed, small samples for oxygen index measurement and UL94-classification were taken from the profiles. Oxygen index was $32 \%$ for the profiles with pre-treated wood flour and $29 \%$ for the profiles with untreated wood flour. Samples from both formulations also achieved V0-classification in the UL94 test, hence, the results previously obtained using small injection-moulded samples were confirmed. The results for the SBI tests are shown in Table 7, and the classification criteria for SBI testing are shown in Table 8. The formulation with pre-treated wood flour reached classification $\mathrm{C}-\mathrm{s} 3, \mathrm{~d} 0$ according to DIN EN 13501-1 which means that the material is hardly flammable according to the German DIN 4102-1 (1998). In comparison, the formulation with untreated wood flour was classified as D-s2, d0 according to DIN EN 13501-1, i.e., the material is normally flammable according to DIN 4102-1. In both cases (untreated and pre-treated wood flour), lateral flame spread (LFS) did not reach the far edge of the long wing specimen during the first $1500 \mathrm{~s}$ of the test.

The formulation with 55\% of wood flour listed in Table 7 was extruded in another project and differs in composition as well as in shape of the profile and processing conditions (Schirp and Barrio 2018). The profiles with 55\% pre-treated wood flour achieved even better classification than the profiles with $42 \%$ pre-treated wood flour from this project and reached classification B-s2, d0. The profiles consisted of $55 \%$ pre-treated wood flour, 23\% HDPE, $1 \%$ lubricant, $2 \%$ coupling agent, 19\% APP (Exolit AP 422), and the shape was a hollow decking profile. In this case, the wood flour pre-treatment was done using APP (10\% Exolit AP 420 based on solid content and wood dry weight). LOI of this formulation was 39-40. Despite the differences in the shape and processing of the extruded profiles, it appears that a higher wood content in WPC (55\% compared to $42 \%$ ) leads to better fire resistance which confirms the results by Stark et al. (2010). The wood flour or fibre itself acts as a fire retardant for the polymer matrix. As the wood filler level increases, the heat release rate decreases. In addition, the presence of wood promotes char layer formation on the profile surface (Seefeldt and Braun 2012a). Furthermore, values for the oxygen index can be used to explain why a high wood content in WPC is beneficial in terms of combustibility. The oxygen index of wood (23.9) is higher than that of pure PP (18), which indicates that a greater quantity of oxygen is required to sustain the combustion of wood. With increasing proportion of wood in WPC, the oxygen index increases, e.g., reaching 20 for $60 \%$ wood flour, indicating the presence of wood has increased the oxygen demand for combustion (Stark et al. 2010).

Seefeldt and Braun (2012a) compared hollow and solid extruded profiles regarding their reaction-to-fire performance and found that while profiles with hollow chambers reduced the fire load, they also displayed higher fire propagation. A direct comparison of hollow and solid extruded profiles based on the same composition in the SBI test would be required to clarify if there are differences in reaction-to fire performance.

Nikolaeva and Kärki (2015) performed cone calorimetry with WPC including zinc borate, melamine and APP. Simulated FIGRA and SBI Euroclass classification results showed

Table 7 SBI results summary

\begin{tabular}{llllllllll}
\hline Formulation & $\begin{array}{l}\text { FIGRA } \\
0.2 \mathrm{MJ} \\
{[\mathrm{W} / \mathrm{s}]}\end{array}$ & $\begin{array}{l}\text { FIGRA } \\
\begin{array}{l}0.4 \mathrm{MJ} \\
{[\mathrm{W} / \mathrm{s}]}\end{array}\end{array}$ & $\begin{array}{l}\mathrm{THR}_{600 \mathrm{~s}} \\
{[\mathrm{MJ}]}\end{array}$ & $\begin{array}{l}\text { SMOGRA } \\
{\left[\mathrm{m}^{2} / \mathrm{s}^{2}\right]}\end{array}$ & $\begin{array}{l}\mathrm{TSP}_{600 \mathrm{~s}} \\
{\left[\mathrm{~m}^{2}\right]}\end{array}$ & Classification \\
\hline HDPE: Apyrol-AP422 & 114.5 & 114.5 & 13.6 & 23.8 & 200.5 & $\mathrm{C}$ & $\mathrm{s} 3$ & $\mathrm{~d} 0$ \\
HDPE: no FR-AP422 & 165.7 & 165.7 & 16.3 & 17.9 & 168.6 & $\mathrm{D}$ & $\mathrm{s} 2$ & $\mathrm{~d} 0$ & \\
HDPE* & 54.6 & 54.6 & 6.4 & 13.7 & 177.3 & $\mathrm{~B}$ & $\mathrm{~s} 2$ & $\mathrm{~d} 0$ & \\
\hline
\end{tabular}

Results are based on one test per formulation. Composition of formulations is shown in Table 1

*With 23\% HDPE and 55\% wood flour, which was treated with 10\% AP420 (based on solids content and dry wood); in addition to differences in composition, a hollow-chamber decking profile was used (Schirp and Barrio 2018)

Table 8 Classification criteria for SBI testing

\begin{tabular}{|c|c|c|c|c|c|}
\hline EU classification & $\mathrm{FIGRA} \mathrm{THR}_{600 \mathrm{~s}} / \mathrm{LFS}$ & & SMOGRA/TSP $_{600 \mathrm{~s}}$ & & Flaming droplets/particles classification \\
\hline $\mathrm{A} 2$ and $\mathrm{B}$ & $\begin{array}{l}\text { FIGRA } \leq 120 \mathrm{~W} / \mathrm{s} \\
\mathrm{THR}_{600 \mathrm{~s}} \leq 7.5 \mathrm{MJ} \\
\text { LFS }<\text { edge of specimen }\end{array}$ & $\mathrm{S} 1$ & $\begin{array}{l}\text { SMOGRA } \leq 30 \mathrm{~m}^{2} / \mathrm{s}^{2} \\
\mathrm{TSP}_{600 \mathrm{~s}} \leq 50 \mathrm{~m}^{2}\end{array}$ & $\mathrm{~d} 0$ & No flaming droplets \\
\hline $\mathrm{C}$ & $\begin{array}{l}\text { FIGRA } \leq 250 \mathrm{~W} / \mathrm{s} \\
\mathrm{THR}_{600 \mathrm{~s}} \leq 15 \mathrm{MJ} \\
\text { LFS }<\text { edge of specimen }\end{array}$ & $\mathrm{S} 2$ & $\begin{array}{l}\mathrm{SMOGRA} \leq 180 \mathrm{~m}^{2} / \mathrm{s}^{2} \\
\mathrm{TSP}_{600 \mathrm{~s}} \leq 200 \mathrm{~m}^{2}\end{array}$ & $\mathrm{~d} 1$ & No flaming droplets/part. persisting $>10 \mathrm{~s}$ \\
\hline $\mathrm{D}$ & FIGRA: $\leq 750 \mathrm{~W} / \mathrm{s}$ & $\mathrm{S} 3$ & - & $\mathrm{d} 2$ & - \\
\hline
\end{tabular}


that the best classification achieved was class $\mathrm{D}$ which could be obtained by using either $30 \%$ zinc borate or $20-30 \%$ APP. The same authors also investigated the reaction-to-fire properties of coextruded WPC containing different fire retardants in the shell layer (Nikolaeva and Kärki 2016). The reference sample without fire-retardant displayed class E in the Euroclass system whereas class D was obtained when FR were included in the shell layer. The best results were obtained with APP. Hence, co-extrusion may be an efficient way to reduce costs for the FR while achieving the same Euroclass rating as with bulk protection.

\section{Conclusion}

Under the conditions of the present investigations, the following conclusions can be drawn:

- For PP-based WPC, it is possible to achieve V0-classification in the UL94 test at $4 \mathrm{~mm}$ sample thickness even without a pre-treatment of the wood flour with FR. However, to achieve the same classification for HDPE-based composites, it appears necessary to pre-treat the wood particles with organic nitrogen-phosphorus compounds.

- The values for the LOI were higher for HDPE-based composites compared to PP-based composites. For HDPE-based composites, in cases where V0-classification was obtained, LOI was 29 or higher. For the PPbased composites, a relatively low LOI of 24 leads to V0-classification@4 mm in most cases. Accordingly, there was no relationship between results obtained in LOI and UL94-tests for the wood-polymer composite formulations tested. However, this was not unexpected because the LOI test is used to determine the minimum concentration of oxygen, in admixture with nitrogen, that will support combustion of small test specimens, while in the UL94 test, the flammability rating of the material is determined.

- In general, low amounts of phosphorus leaching were observed during underwater granulation of compounds. Since exposure time of the compounds to water during underwater granulation is very short, further studies are required to investigate possible leaching of FR from the processed compounds, i.e., during service life of the products.

- After $300 \mathrm{~h}$ of artificial (xenon) weathering, V0-classification of fire-retarded HDPE-based composites was reduced to "not passed" whereas V0-classification of PP-based composites was maintained under the same conditions. However, color change after weathering was higher for fire-retarded PP-based than for HDPE-based composites. Color stability of fire-retarded WPC needs to be further improved.
- Single-burning item (SBI) tests showed that classification C-s3, d0 according to DIN EN 13501-1 can be achieved if pre-treated wood flour is used. The use of untreated wood flour leads to a lower classification (D-s2, d0). In the future, SBI tests with fire-retarded composites after weathering should be performed to determine the durability of the fire-retardant treatments.

- Tensile strength of fire-retarded formulations was reduced only for HDPE-based composites and when underwater granulation was used. Tensile MOE was reduced in most cases for HDPE-based composites but mostly increased for PP-based composites. These results show that it is difficult to draw general conclusions regarding the effects of FR on the mechanical performance, and that each formulation needs to be carefully evaluated, also in terms of processability.

- When wood particles are pre-treated with FR (Exolit AP 420 or Apyrol NCE) and APP is added during compounding, swelling and water uptake of the composite are reduced compared to when APP is added during the compounding step only. This may be explained with esterification of the wood particles by the FR which causes a reduction in water uptake. Hence, an important conclusion is that a combined treatment of wood and polymer provides a benefit not only in terms of fire resistance but also in terms of reduced water uptake.

- The most important conclusion is that pre-treatment of the wood particles used in extrusion (HDPE-based composites) has a positive effect on the fire performance of the composites, albeit at a higher cost. The technical benefit may outweigh the additional costs and justify the use of fire-retarded wood flour. Further research into the durability of FR-treated WPC is needed to enable the use of WPC in facades or other building products.

Acknowledgements We thank the Federal Ministry of Food and Agriculture (BMEL) and their funding agency Fachagentur Nachwachsende Rohstoffe (FNR) e.V. for funding of this research project (FKZ 22010212), and companies Rettenmaier \& Söhne GmbH + Co KG (Rosenberg), Linotech GmbH\&Co.KG (Forst), Natur-in-Form GmbH (Redwitz a.d. Rodach) and all suppliers of fire-retardants for their generous support in this project. We kindly acknowledge technical support and helpful suggestions from our colleagues at Fraunhofer WKI.

Funding Open Access funding enabled and organized by Projekt DEAL.

\section{Declarations}

Conflict of interest On behalf of all authors, the corresponding author states that there is no conflict of interest.

Open Access This article is licensed under a Creative Commons Attribution 4.0 International License, which permits use, sharing, adaptation, distribution and reproduction in any medium or format, as long 
as you give appropriate credit to the original author(s) and the source, provide a link to the Creative Commons licence, and indicate if changes were made. The images or other third party material in this article are included in the article's Creative Commons licence, unless indicated otherwise in a credit line to the material. If material is not included in the article's Creative Commons licence and your intended use is not permitted by statutory regulation or exceeds the permitted use, you will need to obtain permission directly from the copyright holder. To view a copy of this licence, visit http://creativecommons.org/licenses/by/4.0/.

\section{References}

Abu Bakar MB, Mohd Ishak ZA, Mat Taib R, Rozman HD, Mohamad Jani S (2010) Flammability and mechanical properties of wood flour-filled polypropylene composites. J Appl Polym Sci 116:2714-2722

Anonymous (2020) https://wiki.polymerservice-merseburg.de/index. php/Oberflächenenergie. Accessed 17 Nov 2020

Ayrilmis N, Jarusombuti S, Fueangvivat V, Bauchongkol P (2011) Effect of thermal-treatment of wood fibres on properties of flatpressed wood plastic composites. Polym Degrad Stab 96:818-822

Borysiak S, Paukszta HM (2006) Flammability of wood-polypropylene composites. Polym Degrad Stab 91:3339-3343

Bouafif H, Koubaa A, Perré P, Cloutier A, Riedl B (2009) Wood particle/high-density polyethylene composites: thermal sensitivity and nucleating ability of wood particles. J Appl Polym Sci 113:593-600

Butylina S, Martikka O, Kärki T (2011) Properties of wood fibre-polypropylene composites: Effect of wood fiber source. Appl Compos Mater 18:101-111

Chapple S, Anandjiwala RJ (2010) Flammability of natural fiber-reinforced composites and strategies for fire retardancy: a review. J Thermopl Comp Mat 23:871-893

DIN 4102-1 (1998) Fire behavior of building materials and building components-Part 1: building materials, terminology, requirements and tests. Deutsches Institut für Normung e.V, Berlin

DIN EN 13501-1 (2010) Fire classification of construction products and building elements-Part 1: classification with data from reaction to fire tests. Deutsches Institut für Normung e.V, Berlin

DIN EN 13823 (2002) Reaction to fire tests for building productsbuilding products excluding floorings exposed to the thermal attack by a single burning item. Deutsches Institut für Normung e.V, Berlin

DIN EN 15534-1 (2018) Composites made from cellulose-based materials and thermoplastics (usually called wood-polymer composites (WPC) or natural fibre composites (NFC)) —Part 1: test methods for characterization of compounds and products. Deutsches Institut für Normung e.V, Berlin

DIN EN 60695-11-10 (2014) Fire hazard testing-Part 11-10: Test flames-50 W horizontal and vertical flame test methods. Deutsches Institut für Normung e.V, Berlin

DIN EN ISO 11885 (2009) Water quality-determination of selected elements by inductively coupled plasma optical emission spectrometry (ICP-OES). Deutsches Institut für Normung e.V, Berlin

DIN EN ISO 4589-2 (2006) Plastics-determination of burning behaviour by oxygen index-part 2: ambient-temperature test. Deutsches Institut für Normung e.V., Berlin

DIN EN ISO 4892-2A (2009) Plastics-methods of exposure to laboratory light sources-part 2: xenon-arc lamps. Deutsches Institut für Normung e.V., Berlin

DIN EN ISO 527-2 (2012) Plastics-determination of tensile properties-Part 2: test conditions for moulding and extrusion plastics. Deutsches Institut für Normung e.V, Berlin
Dominkovics Z, Dányádi L, Pukánszky B (2007) Surface modification of wood flour and its effect on the properties of PP/wood composites. Compos A Appl Sci Manuf 38:1893-1901

Ehrenstein G, Riedel G, Trawiel P (2003) Praxis der Thermischen Analyse von Kunststoffen, 2nd edn. Hanser, Munich

Garcia M, Hidalgo J, Garmendia I, Garcia-Jaca J (2009) Wood-plastics composites with better fire retardancy and durability performance. Compos A Appl Sci Manuf 40:1772-1776

Hämäläinen K, Kärki T (2014) Effects of wood flour modification on the fire retardancy of wood-plastic composites. Eur J Wood Prod 72:703-711

Horacek H (2012) Intumescent flame-retarded building parts manufactured from polyolefins as well as from composites of polyolefins and bismaleinimides. J Appl Polym Sci 126:1511-1526

Hörold S (2014) Phosphorus-based and intumescent flame retardants. In: Papaspyrides CP, Kiliaris P (eds) Chapter 6 in: polymer green flame retardants. Elsevier, Oxford

Ibach RE, Clemons CM, Schumann RL (2007) Wood-plastic composites with reduced moisture: effects of chemical modification on durability in the laboratory and field. In: 9th Int conf on wood \& biofiber plastic composites, Madison, May 21-23, 2007

Kiliaris P, Papaspyrides CP (2014) Polymers on fire. In: Papaspyrides $\mathrm{CP}$, Kiliaris $\mathrm{P}$ (eds) Chapter 1 in: polymer green flame retardants. Elsevier, Oxford

Kozlowski R, Wladyka-Przybylak M (2008) Review: flammability and fire resistance of composites reinforced by natural fibers. Polym Adv Technol 19:446-453

Levan SL (1984) Chemistry of fire retardancy: the chemistry of solid wood. American Chemistry Society, Washington, DC

Lowden LA, Hull TR (2013) Flammability behaviour of wood and a review of the methods for its reduction. Fire Sci Rev 2:4

Mngomezulu ME, John MJ, Jacobs V, Luyt AS (2014) Review on flammability of biofibres and biocomposites. Carbohydr Polym 111:149-182

Nikolaeva M, Kärki T (2011) A review of fire retardant processes and chemistry, with discussion of the case of wood-plastic composites. Baltic For 17(2):314-326

Nikolaeva M, Kärki T (2015) Reaction-to-fire properties of woodpolypropylene composites containing different fire retardants. Fire Technol 51:53-65

Nikolaeva M, Kärki T (2016) Influence of fire retardants on the reaction-to-fire properties of coextruded wood-polypropylene composites. Fire Mater 40:535-543

Pfaendner R (2014) (Photo)oxidative stabilization of flame-retarded polymers. In: Papaspyrides CP, Kiliaris P (eds) Chapter 13 in: polymer green flame retardants. Elsevier, Oxford

Schirp A, Barrio A (2018) Fire retardancy of polypropylene composites reinforced with rice husks: From oxygen index measurements and cone calorimetry to large-scale single-burning item tests. J Appl Polym Sci 135(37):46654

Schirp A, Hellmann A (2019) Fire retardancy improvement of high-density polyethylene composites based thermomechanical pulp treated with ammonium polyphosphate. Polym Comp 40:2410-2423

Schirp A, Su S (2016) Effectiveness of pre-treated wood particles and halogen-free flame retardants used in wood-plastic composites. Polym Degrad Stab 126:81-92

Schirp A, Plinke B, Napolow D (2015) Effectiveness of organic and inorganic pigments for mass colouration of thermo-mechanical pulp used in wood-plastic composites. Eur J Wood Prod 73:5-16

Seefeldt H, Braun U (2012a) A new flame retardant for wood materials tested in wood-plastic composites. Macromol Mater Eng 297:814-820

Seefeldt H, Braun U (2012b) Burning behavior of wood-plastic composite decking boards in end-use conditions: the effects of geometry, material composition and moisture. J Fire Sci 30(1):41-54 
Spear MJ (2015) Preservation, protection and modification of wood composites. In: Ansell MP (ed) Chapter 11 in: Wood composites; woodhead publishing series in composites science and engineering. Elsevier, Oxford

Stark NM, Mueller S, White R, Osswald T (2009) Effect of fire retardants on heat release rate of wood flour-polyethylene composites. In: 10th Int conf on wood \& biofiber plastic comp, Madison, WI, USA, pp 103-104

Stark NM, White RH, Mueller SA, Osswald TA (2010) Evaluation of various fire retardants for use in wood flour-polyethylene composites. Polym Degrad Stab 95:1903-1910

Turku I, Kärki T (2016) Accelerated weathering of fire-retarded woodpolypropylene composites. Compos Part A 81:305-312

Turku I, Kärki T, Puurtinen A (2018) Flammability of wood plastic composites prepared from plastic waste. Fire Mater 42:198-201

Wang W, Zhang S, Wang F, Yan Y, Li J, Zhang W (2016) Effect of microencapsulated ammonium polyphosphate on flame retardancy and mechanical properties of wood flour/polypropylene composites. Polym Comp 37:666-673

Weil ED, Levchik SV (2008) Flame retardants in commercial use or development for polyolefins. J Fire Sci 26(1):5-43
Weil ED, Levchik SV (2016) Flame retardants for plastics and textiles: practical applications, 2nd edn. Hanser, Munich

White RH (1979) Oxygen index evaluation of fire-retardant-treated wood. Wood Sci 12(2):113-121

Xie Y, Krause A, Militz H, Steuernagel L, Mai C (2013) Effects of hydrophobation treatments of wood particles with an amino alkylsiloxane co-oligomer on properties of the ensuing polypropylene composites. Compos A Appl Sci Manuf 44:32-39

Yin H, Sypaseuth FD, Schubert M, Schoch R, Bastian M, Schartel B (2018) Routes to halogen-free flame-retardant polypropylene wood plastic composites. Polym Advan Technol 30(1):187-202

Zhang S, Horrocks AR (2003) A review of flame retardant polypropylene fibres. Prog Polym Sci 28(11):1517-1538

Publisher's Note Springer Nature remains neutral with regard to jurisdictional claims in published maps and institutional affiliations. 